Cochrane Database of Systematic Reviews

\title{
Early discontinuation of antibiotics for febrile neutropenia versus continuation until neutropenia resolution in people with cancer
} (Review)

Stern A, Carrara E, Bitterman R, Yahav D, Leibovici L, Paul M

Stern A, Carrara E, Bitterman R, Yahav D, Leibovici L, Paul M.

Early discontinuation of antibiotics for febrile neutropenia versus continuation until neutropenia resolution in people with cancer.

Cochrane Database of Systematic Reviews 2019, Issue 1. Art. No.: CD012184.

DOI: 10.1002/14651858.CD012184.pub2.

www.cochranelibrary.com

Early discontinuation of antibiotics for febrile neutropenia versus continuation until neutropenia resolution in people with cancer (Review) 
TABLE OF CONTENTS

HEADER 1

ABSTRACT

PLAIN LANGUAGE SUMMARY

SUMMARY OF FINDINGS

BACKGROUND

OBJECTIVES

METHODS

RESULTS

Figure 1.

Figure 2.

Figure 3.

DISCUSSION

AUTHORS' CONCLUSIONS

ACKNOWLEDGEMENTS

REFERENCES

CHARACTERISTICS OF STUDIES

DATA AND ANALYSES

Analysis 1.1. Comparison 1 Early discontinuation versus treatment until neutropenia resolution, Outcome 1 Mortality. ..........

Analysis 1.2. Comparison 1 Early discontinuation versus treatment until neutropenia resolution, Outcome 2 Mortality - risk difference, by day of randomisation.

Analysis 1.3. Comparison 1 Early discontinuation versus treatment until neutropenia resolution, Outcome 3 Mortality - risk difference, per protocol AG2017.

Analysis 1.4. Comparison 1 Early discontinuation versus treatment until neutropenia resolution, Outcome 4 Mortality - by inclusion of febrile vs afebrile participants.

Analysis 1.5. Comparison 1 Early discontinuation versus treatment until neutropenia resolution, Outcome 5 Mortality - by allocation concealment.

Analysis 1.6. Comparison 1 Early discontinuation versus treatment until neutropenia resolution, Outcome 6 Total febrile days.

Analysis 1.7. Comparison 1 Early discontinuation versus treatment until neutropenia resolution, Outcome 7 Clinical failure. .... Analysis 1.8. Comparison 1 Early discontinuation versus treatment until neutropenia resolution, Outcome 8 Any bacteraemia.

Analysis 1.9. Comparison 1 Early discontinuation versus treatment until neutropenia resolution, Outcome 9 Any documented infection.

Analysis 1.10. Comparison 1 Early discontinuation versus treatment until neutropenia resolution, Outcome 10 Any fungal infection.

Analysis 1.11. Comparison 1 Early discontinuation versus treatment until neutropenia resolution, Outcome 11 Development of resistance.

ADDITIONAL TABLES

APPENDICES

CONTRIBUTIONS OF AUTHORS

DECLARATIONS OF INTEREST

SOURCES OF SUPPORT

DIFFERENCES BETWEEN PROTOCOL AND REVIEW

INDEX TERMS 
[Intervention Review]

\section{Early discontinuation of antibiotics for febrile neutropenia versus continuation until neutropenia resolution in people with cancer}

Anat Stern'1, Elena Carrara², Roni Bitterman¹, Dafna Yahav³, Leonard Leibovici³, Mical Paul1

1Division of Infectious Diseases, Rambam Health Care Campus, Haifa, Israel. 2Infectious Diseases, Policlinico San Matteo Hospital, Pavia, Italy. ${ }^{3}$ Department of Medicine E, Beilinson Hospital, Rabin Medical Center, Petah Tikva, Israel

Contact address: Anat Stern, Division of Infectious Diseases, Rambam Health Care Campus, Ha-aliya 8 St, Haifa, 33705, Israel. a_shteren@rambam.health.gov.il.

Editorial group: Cochrane Gynaecological, Neuro-oncology and Orphan Cancer Group.

Publication status and date: New, published in Issue 1, 2019.

Citation: Stern A, Carrara E, Bitterman R, Yahav D, Leibovici L, Paul M. Early discontinuation of antibiotics for febrile neutropenia versus continuation until neutropenia resolution in people with cancer. Cochrane Database of Systematic Reviews 2019, Issue 1. Art. No.:

CD012184. DOI: 10.1002/14651858.CD012184.pub2.

Copyright ( 2019 The Cochrane Collaboration. Published by John Wiley \& Sons, Ltd.

\section{A B S T R A C T}

\section{Background}

People with cancer with febrile neutropenia are at risk of severe infections and mortality and are thus treated empirically with broadspectrum antibiotic therapy. However, the recommended duration of antibiotic therapy differs across guidelines.

\section{Objectives}

To assess the safety of protocol-guided discontinuation of antibiotics regardless of neutrophil count, compared to continuation of antibiotics until neutropenia resolution in people with cancer with fever and neutropenia, in terms of mortality and morbidity. To assess the emergence of resistant bacteria in people with cancer treated with short courses of antibiotic therapy compared with people with cancer treated until resolution of neutropenia.

\section{Search methods}

We searched the Cochrane Central Register of Controlled Trials (CENTRAL; 2018, Issue 10) in the Cochrane Library, MEDLINE, Embase, and LILACS up to 1 October 2018. We searched the metaRegister of Controlled Trials and the US National Institutes of Health Ongoing Trials Register ClinicalTrials.gov for ongoing and unpublished trials. We reviewed the references of all identified studies for additional trials and handsearched conference proceedings of international infectious diseases and oncology and haematology conferences.

\section{Selection criteria}

We included randomised controlled trials (RCTs) that compared a short antibiotic therapy course in which discontinuation of antibiotics was guided by protocols regardless of the neutrophil count to a long course in which antibiotics were continued until neutropenia resolution in people with cancer with febrile neutropenia. The primary outcome was 30-day or end of follow-up all-cause mortality.

\section{Data collection and analysis}

Two review authors independently reviewed all studies for eligibility, extracted data, and assessed risk of bias for all included trials. We calculated risk ratios (RRs) with 95\% confidence intervals (CIs) whenever possible. For dichotomous outcomes with zero events in both arms of the trials, we conducted meta-analysis of risk differences (RDs) as well. For continuous outcomes, we extracted means with standard deviations (SD) from the studies and computed mean difference (MD) and 95\% Cl. If no substantial clinical heterogeneity was found, trials were pooled using the Mantel-Haenszel fixed-effect model. 


\section{Main results}

We included eight RCTs comprising a total of 662 distinct febrile neutropenia episodes. The studies included adults and children, and had variable design and criteria for discontinuation of antibiotics in both study arms. All included studies but two were performed before the year 2000. All studies included people with cancer with fever of unknown origin and excluded people with microbiological documented infections.

We found no significant difference between the short-antibiotic therapy arm and the long-antibiotic therapy arm for all-cause mortality ( $R R$ 1.38, $95 \% \mathrm{Cl} 0.73$ to 2.62 ; RD $0.02,95 \% \mathrm{Cl}-0.02$ to 0.05 ; low-certainty evidence). We downgraded the certainty of the evidence to low due to imprecision and high risk of selection bias. The number of fever days was significantly lower for people in the short-antibiotic treatment arm compared to the long-antibiotic treatment arm (mean difference $-0.64,95 \% \mathrm{Cl}-0.96$ to $-0.32 ;\left.\right|^{2}=30 \%$ ). In all studies, total antibiotic days were fewer in the intervention arm by three to seven days compared to the long antibiotic therapy. We found no significant differences in the rates of clinical failure (RR $1.23,95 \% \mathrm{Cl} 0.85$ to 1.77 ; very low-certainty evidence). We downgraded the certainty of the evidence for clinical failure due to variable and inconsistent definitions of clinical failure across studies, possible selection bias, and wide confidence intervals. There was no significant difference in the incidence of bacteraemia occurring after randomisation ( $\mathrm{RR} 1.56,95 \% \mathrm{Cl} 0.91$ to 2.66 ; very low-certainty evidence), while the incidence of any documented infections was significantly higher in the short-antibiotic therapy arm (RR $1.67,95 \% \mathrm{Cl} 1.08$ to 2.57 ). There was no significant difference in the incidence of invasive fungal infections ( $\mathrm{RR} 0.86,95 \% \mathrm{Cl} 0.32$ to 2.31 ) and development of antibiotic resistance (RR $1.49,95 \% \mathrm{Cl} 0.62$ to 3.61 ). The data on hospital stay were too sparse to permit any meaningful conclusions.

\section{Authors' conclusions}

We could make no strong conclusions on the safety of antibiotic discontinuation before neutropenia resolution among people with cancer with febrile neutropenia based on the existing evidence and its low certainty. Results of microbiological outcomes favouring long antibiotic therapy may be misleading due to lower culture positivity rates under antibiotic therapy and not true differences in infection rates. Welldesigned, adequately powered RCTs are required that address this issue in the era of rising antibiotic resistance.

\section{PLAIN LANGUAGE SUMMARY}

\section{Stopping antibiotic therapy early versus continuing until normal neutrophil count in people with cancer with fever and low neutrophil counts}

\section{Review question}

People with cancer who are treated with chemotherapy may have a low number of white blood cells, a condition known as neutropenia. White blood cells are crucial to defending the immune system against infection. In people with neutropenia who develop fever, it is unknown whether it is safe to stop giving antibiotics before the white blood cell count returns to normal or whether it is better to continue antibiotics until the white blood cell count recovers (usually to a number higher than 500 cells per microlitre).

\section{Background}

Neutrophils are a type of white blood cell crucial to the defence of the immune system against many infective pathogens including bacteria. People with cancer receiving chemotherapy suffer from decreased production of neutrophils, which means that they are exposed to severe, life-threatening infections. When a cancer patient with neutropenia develops fever, it is crucial to start broad-range antibacterial treatment as soon as possible in order to lower the risk of death and serious complications. To date, the best duration of course of antibiotics to give is unclear. The continuation of antibiotics beyond the required duration might result in the development of side effects and resistant bacteria.

\section{Search date}

The evidence is current to 1 October 2018.

\section{Study characteristics}

We included eight studies involving people with neutropenia and fever and comparing short antibiotic therapy to long antibiotic therapy until normalisation of neutrophils. A total of 662 episodes of fever in people with neutropenia were randomly assigned to a treatment group (314 to short antibiotic treatment and 348 to long antibiotic treatment). All trials excluded people who had bacteria growing in any culture before the time of randomisation. All studies except two excluded people with infection in a specific organ.

\section{Study funding sources}

Three trials did not report funding sources; three were funded by academic sponsors; one had academic sponsorship, but the antibiotics and placebos were provided by pharmaceutical companies; and one was sponsored by government funding.

\section{Key results}

There was no difference in mortality between the short- and long-antibiotic therapy arm. There was no difference in the number of people with severe infections presenting as bacteria in blood. There were more cases of infections with positive cultures in people treated with short antibiotic courses compared to long antibiotic courses, but there was no difference in the rate of unfavourable outcome such as recurrence of fever, need for rehospitalization, and change or restart of antibiotics. We found no differences in the rate of fungal infections and development of antibiotic resistance, with few studies reporting the latter outcome. The number of days with fever was lower for people treated with short antibiotic courses compared to those treated with long antibiotic courses. In all trials the number of antibiotic

Early discontinuation of antibiotics for febrile neutropenia versus continuation until neutropenia resolution in people with cancer 
treatment days was fewer in the short-antibiotic therapy arm by three to seven days compared to the long-antibiotic therapy arm. Data on hospital length of stay were insufficient to permit any meaningful conclusions.

\section{Certainty of the evidence}

The overall certainty of evidence was low or very low, permitting little confidence in the results presented. Most of the included studies were old and not adequately designed. There were also many differences between the studies in terms of design and inclusion criteria. We assessed the certainty of the evidence for the primary outcome of all-cause mortality as low and for the outcomes of clinical failure and bacteraemia occurring after randomisation as very low. 


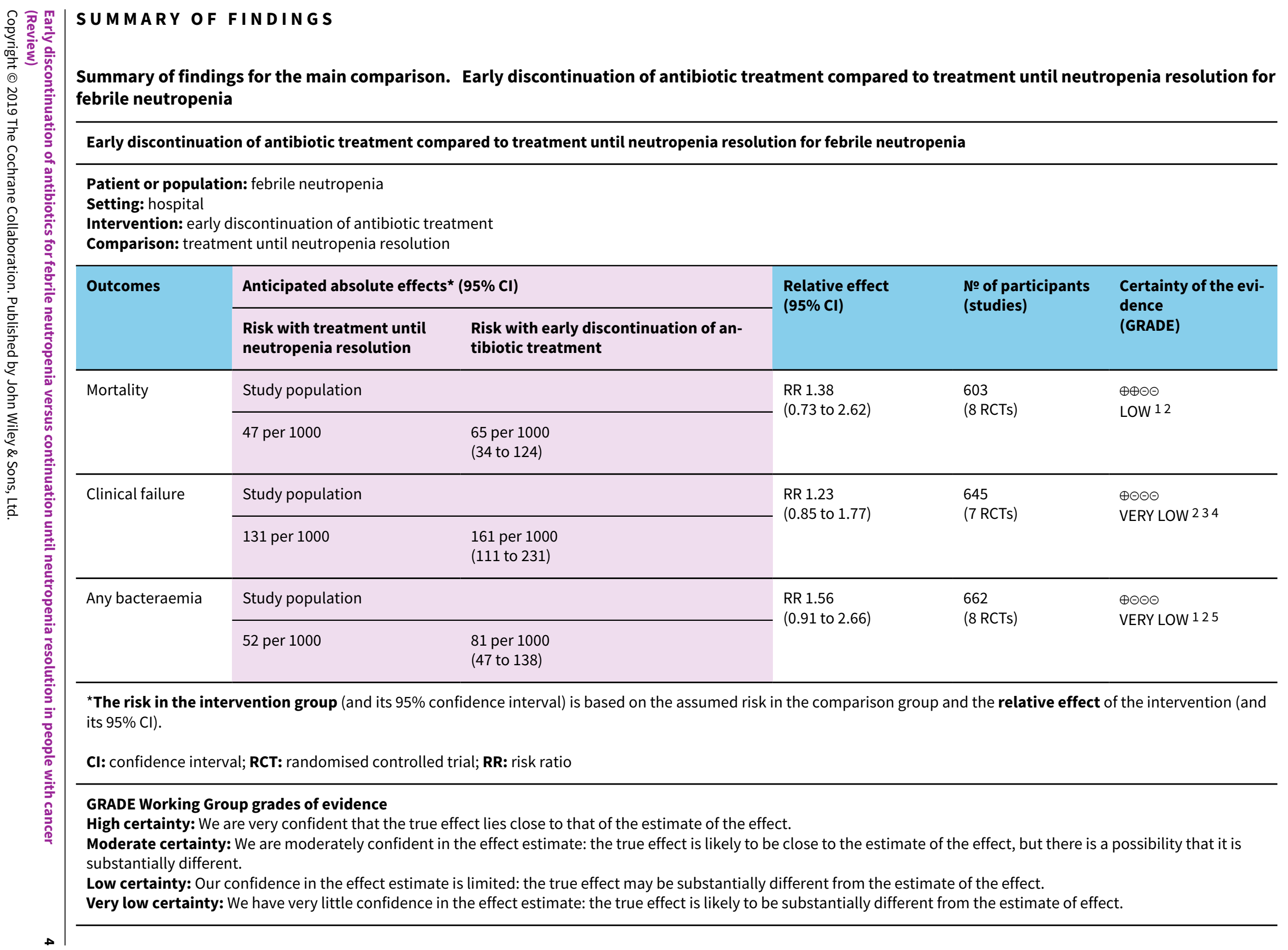

Patient or population: febrile neutropenia

hospital

${ }^{*}$ The risk in the intervention group (and its $95 \%$ confidence interval) is based on the assumed risk in the comparison group and the relative effect of the intervention (and (It) $95 \%$ CI).

C: confidence interval; RCT: randomised controlled trial; RR: risk ratio

substantially different.

Very low certainty: We have very little confidence in the effect estimate: the true effect is likely to be substantially different from the estimate of effect. 

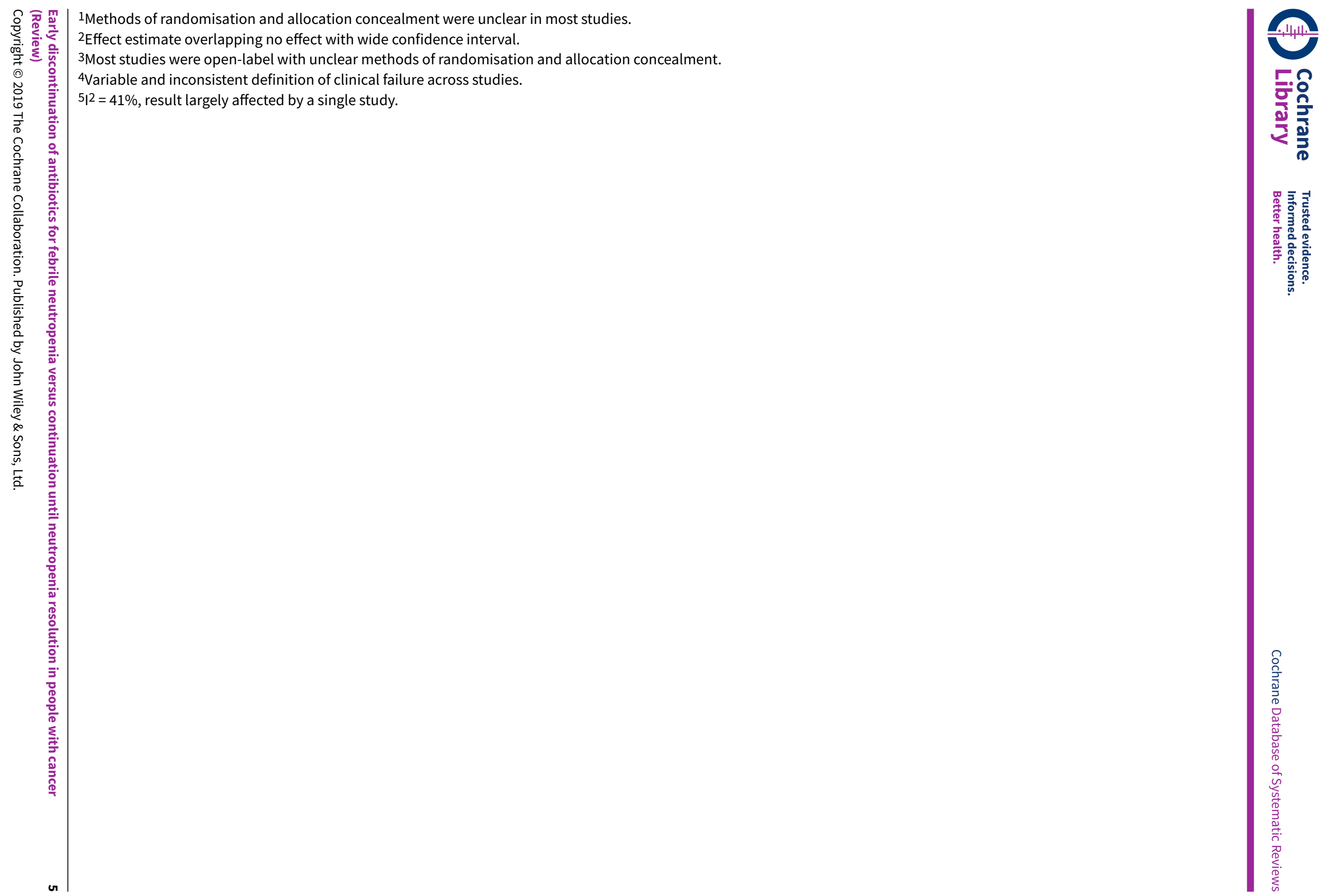


\section{B A C K G R O U N D}

\section{Description of the condition}

People with cancer receiving cytotoxic antineoplastic therapy suffer from decreased myelopoiesis (production of white blood cells in the bone marrow) and from disruption of the integrity of the gastrointestinal mucosa, predisposing them to severe invasive infections. In this population, the magnitude of the neutrophilmediated inflammatory response may be decreased, so that fever may be the earliest and only sign of infection (hence 'febrile neutropenia') (Sickles 1975). The Infectious Diseases Society of America (IDSA) defines fever in neutropenic patients as a single oral temperature of above $38.3^{\circ} \mathrm{C}\left(101^{\circ} \mathrm{F}\right)$ or a temperature of above $38.0{ }^{\circ} \mathrm{C}\left(100.4{ }^{\circ} \mathrm{F}\right)$ sustained for more than one hour in people with neutrophil counts less than 500 cells/ $\mu \mathrm{L}$ or between 500 to 1000 cells $/ \mu \mathrm{L}$ and expected to decline below 500 cells $/ \mu \mathrm{L}$ (Freifeld 2011). The incidence of febrile neutropenia (FN) varies between $10 \%$ and $50 \%$ in people with solid tumours receiving antineoplastic therapy and is reported in $80 \%$ or more of people with haematological malignancies, with an associated mortality rate of about $10 \%$ (Klastersky 2004). The risk of invasive infection in FN is inversely related to the absolute neutrophil count (ANC). Severe neutropenia is defined as an ANC less than 500 cells/ $\mu \mathrm{L}$, and profound neutropenia as an ANC less than 100 cells $/ \mu \mathrm{L}$ (Bow 2013). The risk of clinically important infection is considered significant in people with severe neutropenia and is higher in people with a prolonged duration of neutropenia (more than seven days). Neutropenia resolution is considered a surrogate for marrow recovery and is an acceptable clinical measure for reconstitution of the immune status. It is commonly defined as an ANC rising above 500 cells $/ \mathrm{mm}^{3}$.

The development of FN should trigger the initiation of a rapid work-up and administration of systemic antibiotic treatment aimed at covering the most probable causative organisms (empirical antibiotic therapy) (White 2014). Early and broadspectrum empirical antibiotic therapy has been shown to lower the rate of death and serious complications in people with cancer with fever and neutropenia (Schimpff 1971; Viscoli 2002). The traditional approach was to admit and treat neutropenic people empirically with intravenous broad-spectrum antibiotics at the emergence of fever. However, recent guidelines recommend that carefully selected low-risk people may be candidates for oral or outpatient empirical antibiotic therapy, or both (de Naurois 2010; Freifeld 2011). Numerous studies have sought to stratify people at presentation into those at high risk versus low risk for complications of severe infection. This risk assessment dictates the approach to therapy, including the need for inpatient admission and intravenous (IV) antibiotics. Several clinical prediction rules were developed and validated for children and adult populations with FN (Klaassen 2000b; Klastersky 2000; Talcott 1992). Talcott proposed a model to predict individual patients' risk of complications and death during an FN episode (Talcott 1992). Patients were considered at low risk if they were outpatients at presentation, exhibited no indication for hospitalisation other than $\mathrm{FN}$, and had adequately controlled cancer. The rule was validated prospectively and later tested in a pilot study for its ability to select people for early switch from IV to oral treatment (Talcott 1992). A consensus panel, the Multinational Association for Supportive Care in Cancer (MASCC), developed a set of criteria that are predictors of good prognosis in 'low risk' adult people: acquisition of fever out of hospital, age younger than 60 years, absent to moderate symptoms, no hypotension, no chronic bronchitis, and a background of either a solid tumour or haematological malignancy with no history of fungal infection. While receiving conventional therapy, people with a score equal to or greater than 21 had a low rate of serious medical complication (6\%) and only $1 \%$ mortality (Klastersky 2000). Using these factors, a simple and easy-to-use MASCC risk index score has been developed, and its clinical prediction rule for identification of low-risk patients has been validated. Oral antibiotic treatment for low-risk febrile neutropenic patients has been shown to be as safe as intravenous treatment (Vidal 2013).

Febrile neutropenic patients are additionally classified at the end of the FN episode by whether or not the infectious source for the fever was found. The International Immunocompromised Host Society has classified initial neutropenic fever syndromes into three categories: microbiologically documented infection (MDI), defined when a clinical focus of infection and an associated pathogen are identified; clinically documented infection (CDI), defined when only a clinical focus (e.g. cellulitis, pneumonia) is identified but without the isolation of an associated pathogen; and fever of unexplained origin (FUO), when neither a clinical focus of infection nor a documented pathogen is identified (Immunocompromised Host Society 1990). The large majority of people with febrile neutropenia, both high- and low-risk patients, have unexplained fever (Pizzo 1993).

\section{Description of the intervention}

The intervention addressed in our review concerns the duration of antibiotic therapy for FN and the safety of stopping antibiotics before resolution of the neutropenia. There is currently no consensus between different practice guidelines with regard to the duration of antibiotic therapy. The IDSA clinical practice guidelines for the use of antimicrobial agents in neutropenic people with cancer, published in 2011, state that in people with clinically or microbiologically documented infections, the duration of antibiotic therapy is dictated by the particular organism and site; appropriate antibiotics should continue for at least the duration of neutropenia (until ANC is $>500$ cells $/ \mathrm{mm}^{3}$ ) or longer if clinically necessary. In people with unexplained fever, it is recommended that the initial regimen be continued until there are clear signs of marrow recovery. An option is given, if an appropriate treatment course has been completed and all signs and symptoms of a documented infection have resolved, to resume oral fluoroquinolone prophylaxis until marrow recovery (Freifeld 2011). On the opposite extreme, the Fourth European Conference on Infections in Leukemia (ECIL-4) guidelines addressing high-risk patients, state that in people without a documented infection, IV empirical antibacterial therapy may be discontinued after 72 hours or more in people who have been afebrile for 48 hours or more and are stable, irrespective of neutrophil count or expected duration of neutropenia. In documented infections, it is recommended that targeted antibiotics be continued until infection is microbiologically eradicated and all clinical signs of infection are resolved for at least seven days, of which at least four days are afebrile (Averbuch 2013a; Averbuch 2013b). The recommendations of the IDSA, ECIL-4, and other guidelines on the duration of antibiotic therapy for febrile neutropenia are summarised in Table 1. Unlike the IDSA guidelines, most practice guidelines do not base the duration of antibacterial therapy on the neutrophil count recovery. Recommendations are variable and 
sometimes imprecise, leaving clinicians in doubt regarding the appropriate course of management.

\section{How the intervention might work}

The rationale behind continuing antibiotic therapy until marrow recovery is that the risk of severe, life-threatening infection remains significant as long as neutropenia persists and that existing infections might not be diagnosed as long as neutropenia exists (Bodey 2000). Neutrophils are necessary to mount an inflammatory reaction at the site of infection and thus, for example, with neutropenia a skin infection might not be apparent (Sickles 1975), or pneumonia might not present with an infiltrate on imaging (Barloon 1991; Oude Nijhuis 2003). On the other hand, continuation of antibiotic treatment until neutropenia resolution is not harmless: prolonged broad-spectrum antimicrobial therapy is linked to development and selection of antibacterial-resistant bacteria, Clostridium difficile infections, and fungal infections (Averbuch 2013a).

The effect of prolonged broad-spectrum antibiotic therapy on the emergence of antibacterial resistance is well-demonstrated. Several studies have shown prior antibiotic therapy to be a significant independent risk factor for multidrug-resistant gramnegative infections in hospitalised people with cancer (Gudiol 2011; Ram 2012). Specifically, carbapenem treatment has been linked to carbapenem-resistant gram-negative bacteraemia, and these bacteraemias were associated with an adjusted five-fold risk of death (Andria 2015). Similarly, a case control study showed that prolonged therapy with carbapenems (seven days or longer) is significantly associated with multidrug-resistant Pseudomonas infections in people with cancer (Ohmagari 2005). The development of $C$ difficile-associated diarrhoea (CDAD) in people with cancer is also linked to prior antibiotic therapy (Apostolopoulou 2011). A retrospective study analysing 134 acute myeloid leukaemia patients receiving chemotherapy showed CDAD to be associated with the number of antibiotics administered (two versus one) and the duration of antibiotic therapy (seven versus four days) (Schalk 2010). Antibacterial therapy is also considered a risk factor for invasive fungal infection in people with cancer (Singh 2001). Krcmery and colleagues described 41 cases of breakthrough fungaemia episodes during antifungal prophylaxis or empirical antifungal therapy in people with cancer receiving antineoplastic chemotherapy; all of the people in this series had prior therapy with broad-spectrum antibacterials as a risk factor for fungaemia (Krcmery 1998). Similarly, a multicentre prospective study of people with haematological malignancies undergoing chemotherapy in China showed an association between the use of two or more broad-spectrum antibiotics and the development of invasive fungal infection (Li 2014).

An additional potential disadvantage of prolonged antibacterial therapy is the risk of developing adverse effects including nausea or vomiting (e.g. from meropenem use), hypokalaemia (e.g. from beta-lactam agents such as piperacillin-tazobactam), cutaneous hypersensitivity reactions (e.g. from beta-lactam agents or clindamycin), disulfiram (Antabuse)-like reactions (e.g. from metronidazole), myelosuppression (e.g. from oxazolidinone-related thrombocytopenia), nephrotoxicity (e.g. from aminoglycoside use), or changes in the serum creatinine secondary to ion exchange (e.g. from trimethoprimsulfamethoxazole use).

\section{Why it is important to do this review}

In an era of a constant and worldwide rise in antibacterial resistance, it seems crucial to attempt to minimise unnecessary use of antibiotics and shorten the duration of broad-spectrum antibiotic therapy when possible without compromising patient safety. To date, the existing data regarding the optimal duration of antibiotic therapy for febrile neutropenia in people with cancer is not robust, and guidelines differ in their recommendations. This systematic review aimed to provide better evidence regarding the safety of short antibiotic courses, irrespective of neutrophil count, in cancer neutropenic patients with fever of unknown aetiology or documented infection.

\section{O B JECTIVES}

To assess the safety of protocol-guided discontinuation of antibiotics regardless of neutrophil count, compared to continuation of antibiotics until neutropenia resolution in people with cancer with fever and neutropenia, in terms of mortality and morbidity. To assess the emergence of resistant bacteria in people with cancer treated with short courses of antibiotic therapy compared with people with cancer treated until resolution of neutropenia.

\section{METHODS}

\section{Criteria for considering studies for this review}

\section{Types of studies}

Randomised controlled trials (RCTs).

\section{Types of participants}

Adults ( $\geq 18$ years) and children ( $<18$ years) with fever and neutropenia caused by cancer-related chemotherapy, treated with any antibiotic regimen. We permitted the inclusion of people with neutropenic FUO, CDI, and MDI and documented which of the patient populations the study addressed and whether people with $\mathrm{CDI} / \mathrm{MDI}$ were included.

We defined fever as a single oral temperature higher than $38.3^{\circ} \mathrm{C}$ $\left(101^{\circ} \mathrm{F}\right)$ or a temperature higher than $38.0^{\circ} \mathrm{C}\left(100.4^{\circ} \mathrm{F}\right)$ sustained for more than one hour. We defined neutropenia as an ANC less than 500 cells $/ \mu \mathrm{L}$. If studies used alternative definitions, we included the studies in the review if the definitions were similar to ours, and documented the studies' definitions.

\section{Types of interventions}

Protocol-guided discontinuation of antibiotics before neutropenia resolution compared to continuation of antibiotics until neutropenia resolution.

We recorded the criteria defined for discontinuation of antibiotics, including the precise timing of discontinuation, definitions of defervescence, and neutrophil count defined for neutropenia resolution.

\section{Types of outcome measures}

\section{Primary outcomes}

- Thirty-day mortality from any cause (all-cause mortality). If allcause mortality was not available at 30 days, we used the time point reported by the study and documented it.

Early discontinuation of antibiotics for febrile neutropenia versus continuation until neutropenia resolution in people with cancer 


\section{Secondary outcomes}

- Fever days, defined as the number of consecutive febrile days (starting from the beginning of the febrile neutropenia episode or as defined by the study).

- Total antibiotic days during follow-up/hospitalisation, including initial antibiotic course and any subsequent antibiotic therapy initiated after randomisation.

- Clinical failure, as defined in the study.

- Any bacteraemia developing after the time point defined for the short-course antibiotic arm or after randomisation and during the follow-up period.

- Any documented infection diagnosed after the time point defined for the short-course antibiotic arm or after randomisation and during the follow-up period.

- Any invasive fungal infection diagnosed after randomisation (including invasive Candida infections, any mould infection, and others as defined by the study).

- C difficile infections diagnosed after randomisation.

- Acquisition of multidrug-resistant organisms, defined as any isolation of a resistant pathogen after randomisation, including methicillin-resistant Staphylococcus aureus (MRSA), vancomycin-resistant enterococci (VRE), and multidrugresistant gram-negative (MDR-GN), as defined in the study.

- Secondary infections caused by bacteria resistant to the initial antibiotic treatment, as defined in each trial.

- Number of hospitalisation days.

- Any need for chemotherapy delay as reported in the study.

We extracted data on the definitions of each of the secondary outcomes and the duration of follow-up in the individual studies.

\section{Search methods for identification of studies}

\section{Electronic searches}

We identified studies by conducting a comprehensive search including:

- the Cochrane Central Register of Controlled Trials (CENTRAL; Issue 10, 2018) in the Cochrane Library;

- MEDLINE via Ovid (1946 to September week 3, 2018);

- Embase via Ovid (1980 to 2018 week 40); and

- LILACS (Latin American and Caribbean Health Science Information database (January 1982 to October 2018) (lilacs.bvsalud.org/en).

We searched the following trial registries for ongoing and unpublished trials:

- metaRegister of Controlled Trials (www.controlled-trials.com); and

- US National Institutes of Health Ongoing Trials Register ClinicalTrials.gov (clinicaltrials.gov).

The search strategy is provided for MEDLINE in Appendix 1, Embase in Appendix 2, and CENTRAL in Appendix 3.

\section{Searching other resources}

We reviewed the references of all identified studies for additional trials.
We handsearched the following conference proceedings: European Congress of Clinical Microbiology and Infectious Diseases (2001 to 2018); ICAAC/Annual Meeting of the Infectious Diseases Society of America/ASM-microbe (IDSA) (2001 to 2017); and oncology (American Society of Clinical Oncology (ASCO) annual meeting) and haematology conferences (American Society of Hematology (ASH) annual meeting, European Society for Blood and Marrow Transplantation (EBMT), and European Hematology Association (EHA) annual conferences).

\section{Data collection and analysis}

\section{Selection of studies}

Two review authors (AS and EC or RB) performed the search and inspected the title and abstract of each reference identified. The same review authors copied abstracts that seemed relevant to a Microsoft Word file. Duplicates of abstracts found by different search strategies were removed after revision by AS and EC or RB independently. The same review authors obtained and independently inspected full-text articles for the remaining abstracts, excluding trials not fulfilling the inclusion criteria. Any disagreements were resolved by discussion with a third review author (MP, DY, or LL).

\section{Data extraction and management}

Two review authors (AS and EC) designed a data extraction sheet. Data extracted to the data extraction sheet included study information (e.g. publication status, study years, number of centres), participant information (type of population, inclusion and exclusion criteria, baseline characteristics), information regarding the intervention (type of antibiotic regimen, planned antibiotic duration in each arm), information regarding risk of bias (e.g. randomisation method, allocation concealment, blinding, early stop, incomplete outcome reporting), and information regarding outcomes (mortality, reported secondary outcomes).

Two review authors (AS and EC or RB) independently extracted data from the included trials to the data extraction sheet.

We extracted data preferentially by intention-to-treat, including all individuals randomised in the outcome assessment.

In instances in which a single study provided data on multiple measures of the same outcome, we chose the measure that best fitted our outcome definitions.

For dichotomous outcomes, we recorded the number of participants manifesting the outcome in each group as well as the number of evaluated participants. For continuous outcomes, we documented values as well as the measure chosen to represent the data (e.g. mean with standard deviation, median with interquartile range, etc.).

Any differences in data extraction were resolved by discussion with a third review author (MP, DY, or LL).

\section{Assessment of risk of bias in included studies}

Two review authors ( $\mathrm{AS}$ and EC or RB) independently assessed risk of bias in each study according to the following domains: selection bias (random sequence generation and allocation concealment); performance bias (blinding of participants and personnel); detection bias (blinding of outcome assessment);

Early discontinuation of antibiotics for febrile neutropenia versus continuation until neutropenia resolution in people with cancer 
attrition bias (incomplete outcome data for the primary outcome only, defined as high risk when the number of randomised participants was not given or there was outcome reporting of less than $80 \%$ of the randomised population without justification); and reporting bias (selective reporting). We expressed risk of bias as 'low risk', 'high risk', or 'unclear risk', based on the criteria in the Cochrane Handbook for Systematic Reviews of Interventions (Higgins 2011). Any disagreements were resolved by discussion.

\section{Measures of treatment effect}

For all dichotomous outcomes, we calculated risk ratios (RRs) for individual studies with 95\% confidence intervals (Cls). For continuous outcomes, we extracted means with standard deviations (SD) from the studies. If information was reported differently in a trial, we converted the provided figures to means and SDs using recommended methods (Wan 2014). We computed the mean difference (MD) and $95 \% \mathrm{Cl}$ of each study.

\section{Dealing with missing data}

We requested any missing information from study authors. We did not impute missing outcome data for any of the outcomes.

\section{Assessment of heterogeneity}

We assessed the percentage of variation across studies that could not be ascribed to sampling variation using the $I^{2}$ statistic. We assessed the statistical significance of the heterogeneity using a $\mathrm{Chi}^{2}$ test. We considered a Chi ${ }^{2}$ less than 0.1 and an $\mathrm{I}^{2}$ greater than $50 \%$ to represent substantial heterogeneity. We also visually inspected the forest plots to judge heterogeneity.

\section{Assessment of reporting biases}

We planned to determine publication bias or other small-study effects by constructing funnel plots of effect estimates for the primary outcome in order to visually inspect asymmetry (Sterne 2001). However, as fewer than 10 studies were included in this analysis, we did not construct funnel plots.

\section{Data synthesis}

Two review authors (AS and EC) independently inputted data into Review Manager 5 (RevMan 2014)

We performed a meta-analysis of RRs for the primary outcome and for secondary outcomes whenever possible. We also conducted a meta-analysis of risk differences for dichotomous outcomes with zero events reported in both trial arms. Absolute MDs were pooled for outcomes reported as means. If no substantial clinical heterogeneity was found, trials were pooled using the MantelHaenszel fixed-effect model. When the included studies were too diverse for a meta-analysis or for skewed outcomes reported as medians, we presented the results using a narrative approach or in tables.
We used the GRADE approach to interpret the findings and rate the certainty of evidence (Guyatt 2011), grading the major outcomes (mortality, clinical failure, and bacteraemia development). We analysed the overall certainty of evidence for each outcome individually, downgrading the evidence from 'high certainty' to 'moderate', 'low', or 'very low' depending on the risk of bias, indirectness of evidence, inconsistency, imprecision of effect estimates, and potential publication bias. We took this analysis into account in our conclusions. We used GRADEpro GDT to produce a 'Summary of findings' table with the results of this analysis (GRADEpro GDT 2015).

\section{Subgroup analysis and investigation of heterogeneity}

We planned to conduct subgroup analyses for the primary outcome according to the following patient subgroups.

- Adults versus children (adults defined as 18+ years).

- Documented infection (clinically or microbiologically) versus fever of unknown aetiology.

- High-risk patients versus low-risk patients, preferably defined by MASCC score, but study definitions were accepted and documented.

- Solid tumour patients versus haematologic malignancy patients

- Severity of neutropenia (ANC < 100 versus $100<$ ANC < 500 ), referring to the lowest ANC count documented (nadir of neutropenia).

Lack of data regarding mortality for specific subgroups precluded the predefined subgroup analyses. We performed a post hoc subgroup analysis by inclusion of febrile versus afebrile participants. Since several trials reported no deaths in both study arms, we based subgroup analysis on risk differences.

\section{Sensitivity analysis}

We conducted a sensitivity analysis to assess the effect of allocation concealment on the primary outcome, limiting the analysis to studies at low risk for allocation concealment to prevent the overestimation of effects of studies with inadequate or unclear allocation concealment.

\section{RES U L T S}

\section{Description of studies}

\section{Results of the search}

The searches yielded 4863 references, of which 1099 records were removed because they were duplicates, leaving 3764 records. We used the Cochrane 'RCT Classifier' to eliminate records unlikely to be RCTs. After removing duplicates and trials unlikely to be RCTs, we assessed the titles and the abstracts of 2220 distinct records. After removing irrelevant and clearly ineligible studies, we assessed the full texts of 18 studies for eligibility. We included eight studies in the review and meta-analysis, and excluded 10 studies (Figure 1). 
Figure 1. Study flow diagram.

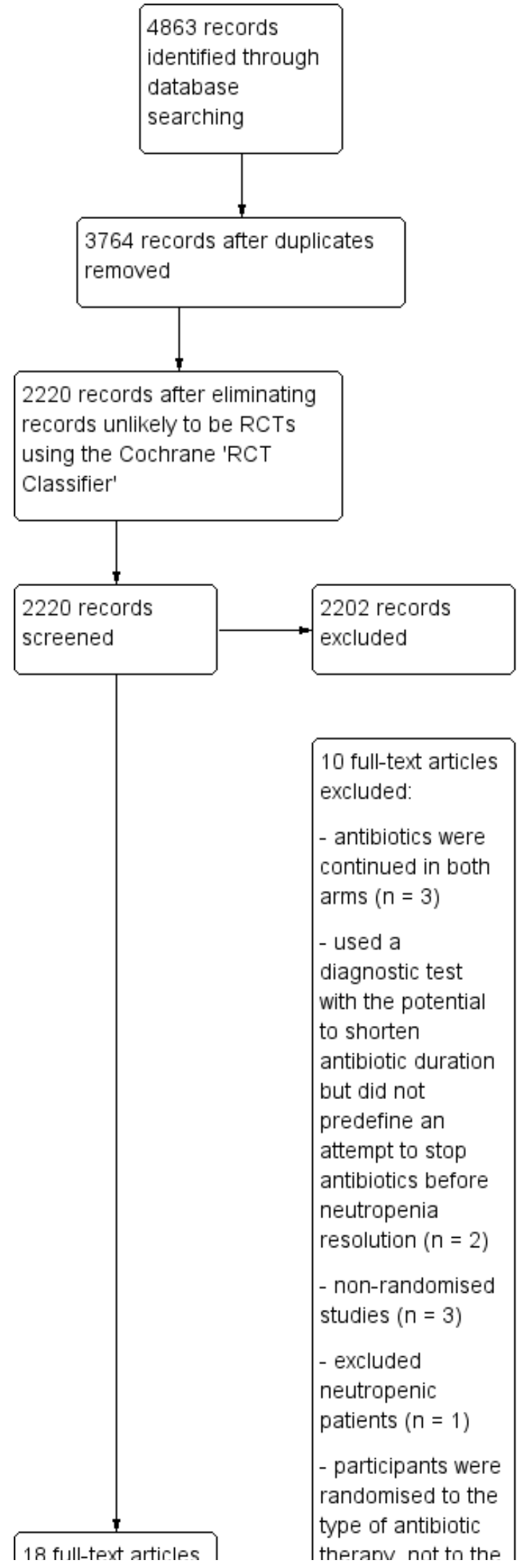


Figure 1. (Continued)

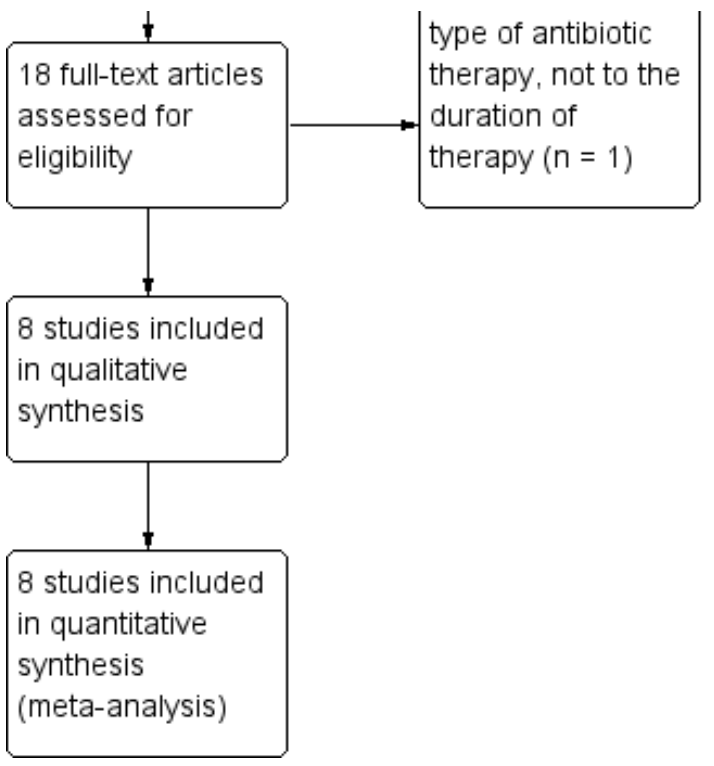

\section{Included studies}

Details of the included studies are summarised in the Characteristics of included studies table. The studies were performed between 1970 and 2016. Two recent studies were multicentre trials including five and six centres, respectively (Aguilar-Guisado 2017; Santolaya 2017), and six studies were singlecentre trials. Five studies were conducted in North America, two in Chile, and one in Spain. Two studies included only adults (AguilarGuisado 2017; Bjornsson 1977). Rodriguez 1973 included adults and children older than 15 years. Two studies included adults and children of any age (Pizzo 1979; Pizzo 1982), while the remaining three studies included only children. Two studies randomised participants (Aguilar-Guisado 2017; Santolaya 2017), while in the remaining six trials the unit of randomisation was neutropenic fever episodes, permitting the inclusion of people more than once into the trial. A total of 662 distinct febrile neutropenia episodes were randomised (314 to the short-antibiotic treatment arm and 348 to the long-antibiotic treatment arm).

Randomisation took place on the third day after fever onset in three trials (Bjornsson 1977; Santolaya 1997; Santolaya 2017); on the fourth day in two trials (Aguilar-Guisado 2017; Rodriguez 1973); and after seven days in two old trials (Pizzo 1979; Pizzo 1982). In Klaassen 2000a, people were randomised after 48 to 120 hours from fever onset. Three trials required the persistence of fever for inclusion (Bjornsson 1977; Pizzo 1982; Santolaya 2017). In contrast, two trials mandated that patients be afebrile in order to be randomised (Klaassen 2000a; Pizzo 1979). Three trials included febrile and afebrile patients (Aguilar-Guisado 2017; Rodriguez 1973; Santolaya 1997), but in Rodriguez 1973 febrile and afebrile patients were randomised separately, and outcome data were reported for each group.

In the intervention arm, antibiotics were stopped at randomisation in all trials, except for in Aguilar-Guisado 2017, in which the intervention was defined as stopping antibiotics only when the participant was afebrile and stable for 72 hours or more, which resulted in antibiotic withdrawal during neutropenia only among $41 / 87(53 \%)$ of participants in the intervention arm. We have primarily reported the intention-to-treat results for this trial, but have also reported an analysis using the modified perprotocol results including only people who remained neutropenic at the time of apyrexia and clinical stability. In all other trials antibiotics were stopped in the intervention arm before neutropenia resolution.

In the control arm, participants continued antibiotic treatment at least until neutropenia resolution in five trials (Aguilar-Guisado 2017;Pizzo 1979; Pizzo 1982; Santolaya 1997). In one trial (Klaassen 2000a) antibiotic treatment was continued for 14 days or until neutropenia resolution. In the remaining studies, a specific time point for antibiotic discontinuation in the control arm was set regardless of the neutrophil count: after 10 days of antibiotic therapy in two studies (Bjornsson 1977; Rodriguez 1973); and after seven days if afebrile and with low C-reactive protein in Santolaya 2017.

Most studies did not restrict inclusion by the type of underlying malignancy or the degree of neutropenia. One study included only people with haematologic malignancies or people following haematopoetic stem cell transplantation with high-risk febrile neutropenia (Aguilar-Guisado 2017), and one study restricted inclusion to low-risk febrile neutropenic patients (Klaassen 2000a). All trials excluded people with cancer who had microbiologically documented bacterial infections, and all but two studies, AguilarGuisado 2017; Santolaya 2017, excluded patients with clinically documented infections. One trial included only people with cancer who had a positive nasopharyngeal sample for a respiratory virus (Santolaya 2017).

Seven trials defined neutropenia as an absolute neutrophil count (ANC) of less than 500/ $\mathrm{mm}^{3}$. Rodriguez 1973 defined neutropenia as an ANC of less than $1000 / \mathrm{mm}^{3}$. The definition of fever varied between studies. One study defined fever a temperature measurement equal to or higher than $38{ }^{\circ} \mathrm{C}$ that was not related to blood transfusion (Bjornsson 1977), and one as a measurement equal to or higher than $38.3^{\circ} \mathrm{C}$ that was not related to blood transfusion (Rodriguez 1973). Fever was defined as one

Early discontinuation of antibiotics for febrile neutropenia versus continuation until neutropenia resolution in people with cancer 
measurement of temperature equal to or higher than $38.5^{\circ} \mathrm{C}$ or multiple measurements equal to or higher than $38{ }^{\circ} \mathrm{C}$ in four studies (Klaassen 2000a; Pizzo 1979; Pizzo 1982; Santolaya 2017), and in one study (Santolaya 1997) it was defined as at least two measurements of temperature equal to or higher than $38.7^{\circ} \mathrm{C}$. The definition of fever was not provided in one study (Aguilar-Guisado 2017).

\section{Excluded studies}

We excluded 10 studies (see Characteristics of excluded studies table). We excluded three studies because antibiotic therapy was continued in both study arms (Calandra 1987; Horowitz 1996; Pegram 1989). In two trials (Idelevich 2015; Lima 2016), a diagnostic test with the potential to shorten antibiotic duration was evaluated (procalcitonin and multiplex polymerase chain reaction, respectively), but there was no predefined attempt to stop antibiotics before neutropenia resolution, and the studies did not report the number of participants who were still neutropenic at the time of treatment discontinuation in the intervention arm. We excluded three trials that were not randomised (Aquino 1997; Cohen 1995; Lee 1998), and one trial that excluded patients who were neutropenic (Aoun 1998). We excluded one study in which participants were randomised to the type of antibiotic therapy but not to the duration of therapy (Cherif 2004).

\section{Risk of bias in included studies}

'Risk of bias' assessment data are detailed in the Characteristics of included studies table and graphically presented in 'Risk of bias' summary graphs (Figure 2 and Figure 3). 
Figure 2. Risk of bias summary: review authors' judgements about each risk of bias item for each included study.

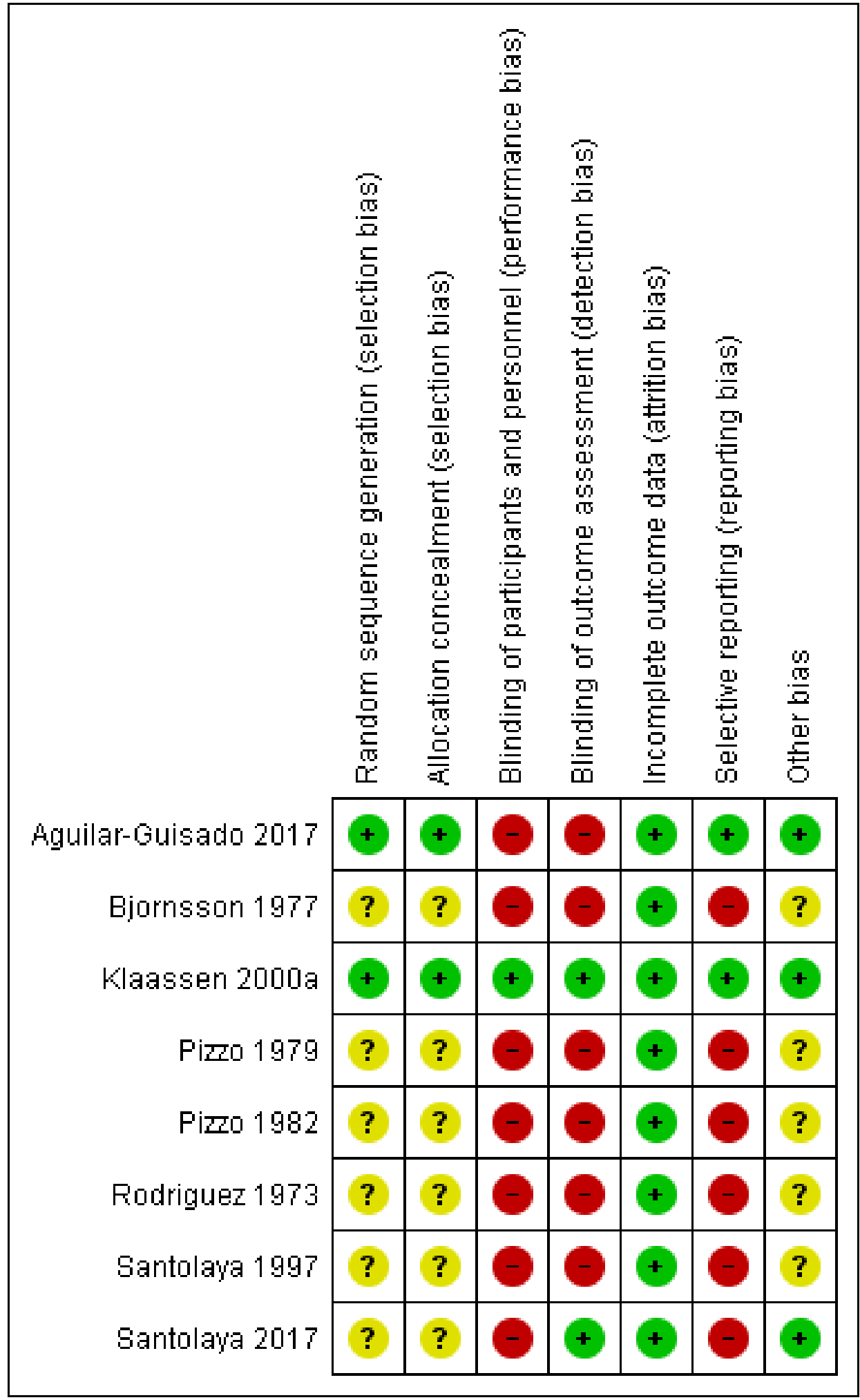

Early discontinuation of antibiotics for febrile neutropenia versus continuation until neutropenia resolution in people with cancer 
Figure 3. Risk of bias graph: review authors' judgements about each risk of bias item presented as percentages across all included studies.

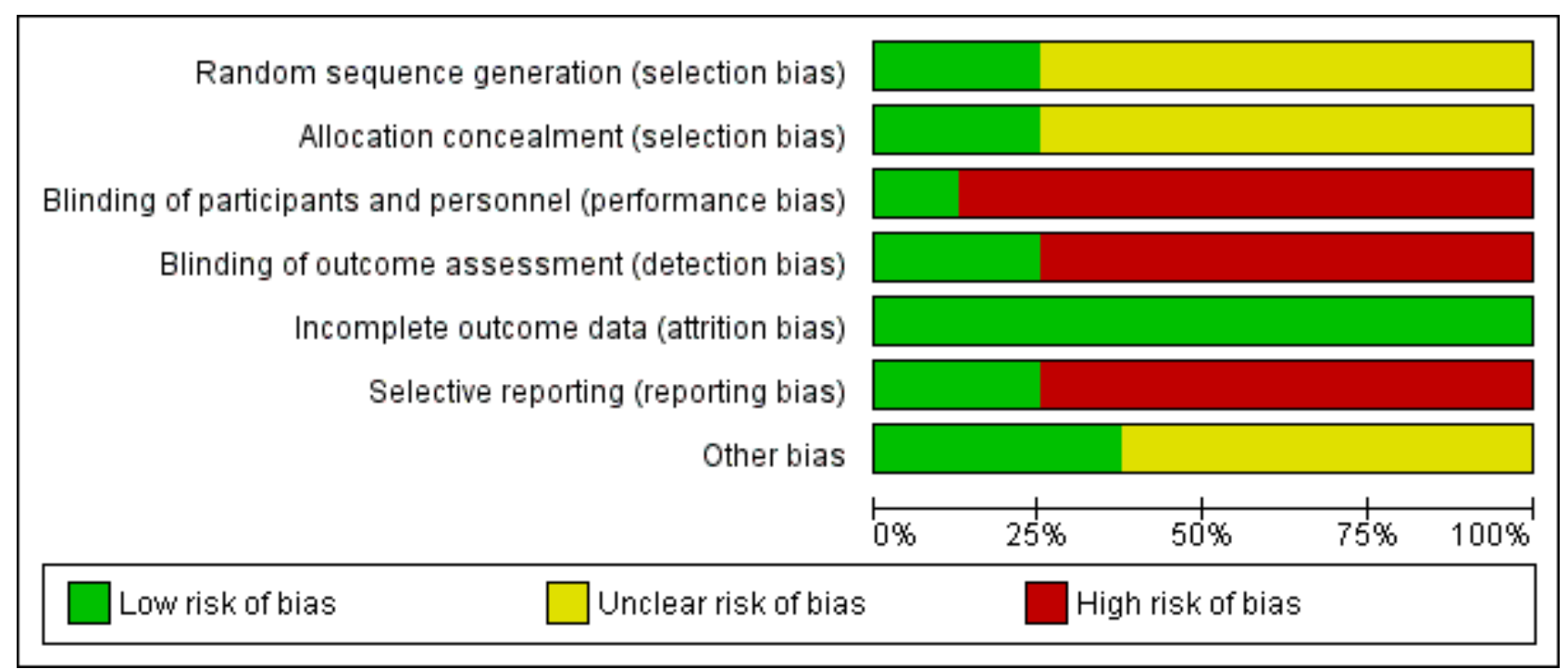

\section{Allocation}

We assessed both random sequence generation and allocation concealment as unclear risk of bias for six studies not reporting allocation methods, and as low risk of bias for two studies (a computer-generated block randomisation list with randomisation performed at the pharmacy in Klaassen 2000a and random-number generator with central randomisation in Aguilar-Guisado 2017).

\section{Blinding}

Seven trials were open-label trials and were therefore assessed as at high risk for performance bias. One trial, Klaassen 2000a, was a double-blinded, placebo-controlled trial and was classified as at low risk for performance bias.

We assessed six trials in which outcome assessors were not blinded as at high risk of detection bias. In two trials (Klaassen 2000a; Santolaya 2017), outcome assessors were blinded, and the risk for detection bias was therefore classified as low.

\section{Incomplete outcome data}

We assessed all included studies as at low risk of attrition bias.

\section{Selective reporting}

Only one trial was registered in a public trial registry (AguilarGuisado 2017); there was full agreement in outcomes reported in the registry compared to the publication, and this trial was therefore classified as at low risk of reporting bias. One nonregistered trial was relatively new and consequently was classified as at high risk of reporting bias (Santolaya 2017). Of the remaining trials, one showed full agreement between the outcomes reported in the methods section and those reported in the results section and was therefore classified as at low risk of bias (Klaassen 2000a), and five trials were assessed as at high risk of reporting bias.

\section{Other potential sources of bias}

In three trials (Aguilar-Guisado 2017; Klaassen 2000a; Santolaya 2017), a sample size calculation was done with no stopping rules, thus we assessed the risk of other bias as low. We assessed the remaining five trials as having an unclear risk of other bias because data regarding sample size calculation and early stop were not available.

\section{Effects of interventions}

See: Summary of findings for the main comparison Early discontinuation of antibiotic treatment compared to treatment until neutropenia resolution for febrile neutropenia

\section{Primary outcome}

\section{All-cause mortality}

All eight included trials (603 participants) reported all-cause mortality. The risk ratio (RR) for death was 1.38 (95\% confidence interval (Cl) 0.73 to 2.62; low-certainty evidence; Analysis 1.1), values higher than 1 representing less risk of mortality in the long-antibiotic therapy arm. We downgraded this evidence to low due to imprecision and high risk of selection bias potentially affecting results (Summary of findings for the main comparison and sensitivity analysis for allocation concealment below). We identified no heterogeneity for this outcome, performed using the fixed-effect model $\left(I^{2}=0 \%\right)$. Three trials reported no deaths in both study arms and thus were not included in the RR calculation. The risk difference (RD) for mortality was $0.02(95 \% \mathrm{Cl}-0.02$ to $0.05 ; I^{2}=17 \%$; Analysis 1.2). This graph is sorted by the duration of the febrile episode before randomisation, and no trend is seen in the RD with increasing time to randomisation. Since the trial design of Aguilar-Guisado 2017 differed from the other trials (only about half of the intervention participants were neutropenic at the time antibiotics were discontinued), we repeated the analysis using the modified per-protocol results of the trial including participants who remained neutropenic after apyrexia and clinical recovery (intervention $0 / 36$ versus control $0 / 30$ deaths). The compiled RD of this analysis was $0.03(95 \% \mathrm{Cl}-0.01$ to 0.06 ; Analysis 1.3$)$.

Early discontinuation of antibiotics for febrile neutropenia versus continuation until neutropenia resolution in people with cancer 


\section{Subgroup analyses}

There were no deaths in all three trials including only children (Klaassen 2000a; Santolaya 1997; Santolaya 2017). Two trials restricted inclusion to adults (Aguilar-Guisado 2017; Bjornsson 1977 - total 9/174 deaths). The remaining trials included children and adults and did not provide mortality data by age group. Lack of data regarding mortality in specific subgroups precluded subgroup analysis for this and other predefined subgroups (severity of neutropenia, low-risk versus high-risk patients, type of underlying malignancy, and presence of documented infection).

In post hoc subgroup analysis by inclusion of febrile versus afebrile participants, the effect on mortality did not differ significantly between subgroups (RD $0.02(95 \% \mathrm{Cl}-0.04$ to 0.08$)$ for febrile and RD $0.07(95 \% \mathrm{Cl}-0.01$ to 0.15$)$ for afebrile participants $(\mathrm{P}=0.36$ for subgroup differences)), with a higher (statistically non-significant) advantage to longer therapy in the subgroup of afebrile participants where deaths occurred only in the intervention arm (Analysis 1.4).

\section{Sensitivity analysis}

The RD for mortality was $-0.02(95 \% \mathrm{Cl}-0.05$ to 0.02$)$ in the studies at low risk of bias for allocation concealment (two trials) compared to $\mathrm{RD} 0.04(95 \% \mathrm{Cl}-0.01$ to 0.09$)$ in the studies at unclear risk of bias for allocation concealment $(P=0.09$ for subgroup differences; Analysis 1.5).

\section{Secondary outcomes}

\section{Total febrile days from febrile neutropenia onset}

Four studies including 458 participants reported the outcome of number of fever days (Aguilar-Guisado 2017; Pizzo 1982; Santolaya 1997; Santolaya 2017). The definitions of this outcome varied among trials. Santolaya 2017 reported the number of fever days after admission; Aguilar-Guisado 2017 reported the total days of fever during follow-up (likely including episodes of recurrent fever); Santolaya 1997 reported the mean duration of fever without specifying whether recurrent fever episodes were included and what the time reference was; and Pizzo 1982, which included only patients who were febrile at randomisation, reported the time from randomisation to defervescence.

Two studies provided data as means and standard deviations (Aguilar-Guisado 2017; Santolaya 1997), and two provided medians with interquartile range (IQR), Santolaya 2017, or range, Pizzo 1982, and thus means and standard deviations (SDs) were computed from the provided figures. The duration of fever was significantly shorter for participants in the short-antibiotic treatment arm compared to the long-antibiotic treatment arm (mean difference (MD) $-0.64,95 \% \mathrm{Cl}-0.96$ to $-0.32 ; \mathrm{I}^{2}=30 \%$; Analysis 1.6$)$. Outcome data as reported by each trial are summarised in Table 2 .

\section{Total antibiotic days}

Three trials (408 participants) reported total antibiotic therapy duration, from randomisation in one trial, Santolaya 1997, and from start of febrile neutropenia in two trials (Aguilar-Guisado 2017; Santolaya 2017). Two trials provided means and SDs (AguilarGuisado 2017; Santolaya 1997), and one provided medians with IQRs. In Aguilar-Guisado 2017, data were presented as days free of antibiotic treatment (defined as 28 days minus the number of antibiotic days), and in Santolaya 1997, quantitative data were provided only for the long-antibiotic therapy arm. Data for this outcome could not be pooled in a meta-analysis. A summary of the results for this outcome in the individual studies is shown in Table 3. The results showed fewer antibiotic days in the short-antibiotic therapy arm in all trials, with this advantage reaching statistical significance in two trials (Aguilar-Guisado 2017; Santolaya 2017). The absolute difference between arms ranged between three and seven days of antibiotics.

\section{Clinical failure}

Seven trials (645 participants) reported clinical failure (AguilarGuisado 2017; Klaassen 2000a; Pizzo 1979; Pizzo 1982; Rodriguez 1973; Santolaya 1997; Santolaya 2017). Clinical failure was defined as the recurrence of fever in two studies (AguilarGuisado 2017; Pizzo 1979); the diagnosis of a documented infection or infectious complication in two studies (Pizzo 1982 and Rodriguez 1973, respectively); the need for readmission while still neutropenic in one study (Klaassen 2000a); the need for antibiotic change or restart in one study (Santolaya 2017); and as a composite of unfavourable outcomes including clinical, laboratory, or microbiological criteria in one study (Santolaya 1997). There was no significant difference in rates of clinical failure between the short- and the long-antibiotic therapy arm (RR 1.23, 95\% Cl 0.85 to $1.77 ; I^{2}=37 \%$; very low-certainty evidence; Analysis 1.7$)$. We downgraded the certainty of the evidence for this outcome to very low due to imprecision, possible selection bias, and indirectness (Summary of findings for the main comparison).

\section{Any bacteraemia}

All eight trials including 662 participants reported the outcome of bacteraemia occurring after randomisation. There were more participants with bacteraemia in the short-antibiotic therapy arm compared to the long-antibiotic therapy arm, but the difference was not statistically significant (RR $1.56,95 \% \mathrm{Cl} 0.91$ to 2.66; $1^{2}=41 \%$; very low-certainty evidence; Analysis 1.8). Excluding Aguilar-Guisado 2017 (due to its special design with no data on bacteraemia given in the modified per-protocol analysis of participants remaining neutropenic at the time antibiotics were discontinued in the intervention arm), there were significantly more participants with bacteraemia in the short-compared to the long-antibiotic therapy arm (RR 2.85, 95\% Cl 1.30 to $6.28 ; \mathrm{I}^{2}=$ $14 \%)$. We downgraded the certainty of this evidence to very low due to selection bias, inconsistency, and imprecision (Summary of findings for the main comparison).

\section{Any documented infection}

All eight included trials (662 participants) reported the diagnosis of any documented bacterial infection after randomisation. There were significantly more participants with documented infections in the short- compared to the long-antibiotic therapy arm (RR 1.67, $95 \% \mathrm{Cl} 1.08$ to $2.57 ; 1^{2}=38 \%$; Analysis 1.9 ).

\section{Any invasive fungal infection}

All eight included trials reported on fungal infections occurring after randomisation. The rate of fungal infections did not differ significantly between the two study arms (RR $0.86,95 \% \mathrm{Cl} 0.32$ to $2.31 ; I^{2}=42 \%$; Analysis 1.10 ). In three trials the risk ratios were not estimable due to zero events in both study arms. The analysis of risk differences also did not show a significant difference between study arms with substantial heterogeneity (RD $0.00,95 \% \mathrm{Cl}-0.04$ to $0.04 ; I^{2}=60 \%$ ). Heterogeneity was due to one outlier study in 
which there were $4 / 6$ events in the short- compared to $0 / 11$ in the long-antibiotic therapy arm (Bjornsson 1977); excluding this study reduced heterogeneity and did not change the results.

\section{Clostridium difficile infections}

One trial reported the development of $C$ difficile infection, with one event in the short-antibiotic therapy arm (Aguilar-Guisado 2017).

\section{MDR acquisition and secondary infections caused by resistant bacteria}

Four trials including 340 participants reported the development of antibiotic resistance (Pizzo 1979; Pizzo 1982; Rodriguez 1973; Santolaya 2017). One trial reported on the isolation of resistant pathogens without further defining it (Pizzo 1979); two trials referred to isolation of bacteria resistant to the antibiotic regimen used in the trial (Pizzo 1982; Rodriguez 1973); and one trial reported the development of extended-spectrum beta-lactamase (ESBL)positive bacteraemia (Santolaya 2017). The rate of resistance development did not differ significantly between the short- and the long-antibiotic therapy arms ( $\mathrm{RR} 1.49,95 \% \mathrm{Cl} 0.62$ to $3.61 ; \mathrm{I}^{2}=23 \%$; Analysis 1.11; excluding one trial with zero events).

\section{Length of hospitalisation}

Two trials reported days of hospitalisation (Santolaya 1997; Santolaya 2017). One trial provided mean and SD, and the second provided the data as median (IQR). The results are presented in Table 4. Both trials favoured the short-antibiotic therapy arm, with a maximal absolute difference of 1 day.

\section{Need for chemotherapy delay}

None of the included trials reported the outcome of need for chemotherapy delay.

\section{DISCUSSION}

\section{Summary of main results}

In this systematic review we addressed the duration of antibiotic therapy in people with cancer with febrile neutropenia. We identified eight RCTs (comprising 662 distinct febrile neutropenia episodes) comparing protocol-guided discontinuation of antibiotics targeting discontinuation of antibiotics before neutropenia resolution to continuation of antibiotic therapy for the traditional duration until neutropenia resolution. The trials had variable design and criteria for discontinuation of antibiotics in both study arms.

We found no significant difference between the short-antibiotic therapy arm and the long-antibiotic therapy arm for all-cause mortality, the primary review outcome (RR $1.38,95 \% \mathrm{Cl} 0.73$ to 2.62; RD $0.02,95 \% \mathrm{Cl}-0.02$ to 0.05 ; low-certainty evidence). Our confidence in the lack of difference is low due to large confidence intervals surrounding the effect estimate and heterogeneity possibly relating to the inclusion of febrile or afebrile patients. The incidence of bacteraemia occurring after randomisation did not differ significantly between groups when including all participants in the analysis (RR $1.56,95 \% \mathrm{Cl} 0.91$ to $2.66 ; \mathrm{I}^{2}=41 \%$; very lowcertainty evidence). When including only participants in whom antibiotics were stopped while the participant was still neutropenic (excluding Aguilar-Guisado 2017), the incidence of bacteraemia was significantly higher in the short-antibiotic therapy arm compared to the long-antibiotic therapy arm (RR 2.85, 95\% Cl 1.30 to 6.28). The incidence of documented infections was also higher in the short-antibiotic therapy arm (RR $1.67,95 \% \mathrm{Cl} 1.08$ to 2.57 ). These differences in microbiological outcomes did not translate into a significant difference in clinical failure (RR $1.23,95 \% \mathrm{Cl}$ 0.85 to $1.77 ; \mathrm{I}^{2}=37 \%$; very low-certainty evidence). We found no significant differences for the other dichotomous outcomes assessed, including invasive fungal infections and development of antibiotic resistance, with few studies reporting the latter outcome and wide confidence intervals for both outcomes. The number of fever days was significantly lower for participants in the intervention arm compared to those in the long-antibiotic treatment arm (MD $-0.64,95 \% \mathrm{Cl}-0.96$ to $\left.-0.32 ; \mathrm{I}^{2}=30 \%\right)$. In all trials, total antibiotic days were fewer in the intervention arm by three to seven days compared to the long-antibiotic therapy arm. The data on hospital stay were too sparse to permit any meaningful conclusions.

\section{Overall completeness and applicability of evidence}

Following a thorough literature search, we found eight RCTs comparing different policies of early antibiotic withdrawal versus antibiotic withdrawal after recovery of neutropenia in people with febrile neutropenia of unknown origin. Participants were randomised from as early as three days following start of intravenous antibiotics in some studies, variably still febrile or afebrile. This time point allowed for safely excluding patients with pre-existing bacteraemia. In the intervention arm, antibiotics were usually stopped at the time of randomisation, while in the control arm antibiotics were continued until neutropenia resolution or until clinical stability for a fixed duration of therapy ranging between 7 and 14 days. Given the diversity of trials in terms of design and inclusion criteria, generalisability of the results may be questioned.

Apart from two relatively recent trials (Aguilar-Guisado 2017; Santolaya 2017), the trials identified for inclusion were relatively old, published between 1990 and 2000 (Klaassen 2000a; Santolaya 1997), or even earlier (Bjornsson 1977; Pizzo 1979; Pizzo 1982; Rodriguez 1973). The epidemiology and management of febrile neutropenia have changed in recent decades (Cohen 2011; Gustinetti 2016), with improvements in supportive care and the ability to follow patients in recent years permitting safer discontinuation of antibiotics during neutropenia.

Two of the included trials restricted inclusion to adults; three included only children; and three included children and adults without providing outcome information for each age group. Consequently, we could not perform subgroup analysis per age group. Recommendations for the duration of antibiotic therapy in febrile neutropenia are similar in children and adult guidelines, and the evidence underlying these recommendations is unsatisfactory for both. Our results for mortality are relevant to adults only, as the event rate among children was null. We could make no conclusions on effects separately for adults and children for the other outcomes.

Most studies included in the review did not restrict inclusion to specific underlying malignancies or stratify results by low- and high-risk patients (the latter with prolonged severe neutropenia) and did not provide data regarding the proportion of participants with febrile neutropenia following haematopoetic stem cell transplantation. Overall, most participants included in the review had haematologic malignancies (76\%), mainly leukaemia, and the 
minority (21\%) had solid tumours. Neutropenia tends to be more profound and prolonged among patients with leukaemia, and the risk for severe infections and complications is markedly higher in this population. The relatively high proportion of this population in the included studies allows application of the results to patients with high-risk febrile neutropenia and by deduction to patients at lower risk.

None of the included trials permitted the inclusion of patients with microbiologically documented infection, and all except two, Aguilar-Guisado 2017; Santolaya 2017, also excluded patients with clinically documented infection. Consequently, the results may be applicable to patients with febrile neutropenia of unknown aetiology but not to those with documented infections.

Ultimately, the rationale for shortening antibiotic treatment duration among neutropenic cancer patients is to reduce selection pressure for antibiotic resistance (Averbuch 2013a). Cancer patients, especially haematologic cancer patients with acute leukaemia and following bone marrow transplantation, are exposed to repeated antibiotic courses for prophylaxis and treatment, thus acquiring multidrug-resistant bacteria. In recent years carbapenem-resistant bacteria have become prevalent in haemato-oncological wards (Andria 2015; Righi 2017). Under these circumstances, shortening the courses of antibiotic treatment becomes imperative. Unfortunately, RCTs are not the appropriate platform to examine the critically important outcome of resistance prevalence. Randomised controlled trials can assess resistance development at the individual level by following the intervention with surveillance of colonisation by resistant bacteria. None of the existing trials reported on resistance surveillance. However, since resistance can be acquired by cross-transmission, the more appropriate platform for assessment of the effects of an intervention shortening antibiotic treatment is to examine rates of resistance over time in units adopting a policy of shortened antibiotic courses.

\section{Quality of the evidence}

The certainty of the evidence was overall very low. As mentioned above, most included studies were old and had suboptimal designs. Only two studies had a low risk of selection bias (adequate random sequence generation and allocation concealment), while the rest had unclear risk, and only one trial used blinding. While it may be true that blinding does not affect the comparison for mortality, an objective outcome, most other outcomes are subjective and liable to bias in open trials (Wood 2008). The assessment of the certainty of evidence for the main outcomes is summarised in Summary of findings for the main comparison. For the primary outcome of all-cause mortality, we assessed the certainty of the evidence as low owing to a serious risk of selection bias and an effect estimate overlapping no effect with a wide confidence interval. We assessed the evidence for the outcomes of clinical failure and bacteraemia occurring after randomisation as of very low certainty for the same reasons, coupled with high risk of performance bias in the case of clinical failure and inconsistency in the case of bacteraemia.

The outcomes dependent on growth of bacteria in blood or other samples (bacteraemia and microbiologically documented infections) may be biased towards lower rates in the long-antibiotic therapy arm due to the lower probability that cultures return positive in the presence of antibiotic treatment. Moreover, in unblinded trials like most of the trials included in this review, there may be a tendency of treating physicians to take more cultures from those patients who are not treated with antibiotics and thus increase the chance of receiving a positive culture. The magnitude of this bias could not have been assessed in the absence of reporting of the actual number of cultures taken in each study arm. Consequently, microbiologic outcomes do not necessarily reflect the incidence of infection.

\section{Potential biases in the review process}

The review authors made attempts to minimise bias in the review process. We conducted a thorough search, including handsearching and searching clinical trial registers and conference proceedings. Two review authors assessed study eligibility, extracted data, and assessed risk of bias in included studies.

This review has several limitations. We compiled trials with varying designs. The number of fever days prior to randomisation and the criteria for antibiotic discontinuation differed across studies. One trial in particular had a different design (Aguilar-Guisado 2017), since randomisation was done after 72 hours from fever onset, but discontinuation of antibiotics in the intervention group was done only after achieving clinical stability. Consequently, by the time antibiotics were withheld, only about half of intervention group participants were still neutropenic. Nevertheless, to avoid attrition bias we included the intention-to-treat population of this trial for all analyses and added a mortality analysis with the modified perprotocol population (those participants who were still neutropenic after achieving clinical stability in both study arms).

We aimed to compare short, protocol-guided antibiotic courses to continuing antibiotics until neutropenia resolution. However, in a subset of trials, the resolution of neutropenia was not the defined criteria for discontinuing antibiotic therapy in the control arm. We included these trials because the predefined duration of treatment for the control arm in these trials was long enough to assume that in the majority of cases neutropenia had resolved by the time antibiotics were withheld.

In most of the included trials the unit of randomisation was episodes of febrile neutropenia and not participants, meaning that participants could have been randomised more than once. This methodology may result in exaggeration of precision of the effect estimate because the outcomes for different episodes in the same participant are not independent.

Finally, for the continuous outcome of fever days, we pooled data after computing means from medians. This is imprecise, since the outcome of fever days naturally has a skewed distribution. This analysis should thus be interpreted with caution.

\section{Agreements and disagreements with other studies or reviews}

Several retrospective and prospective observational studies address the question of antibiotic treatment duration in febrile neutropenia. Studies in paediatric neutropenic patients with fever have shown that discontinuation of intravenous antibiotics seems safe and effective in selected paediatric cancer patients such as those with neutropenia lasting more than seven days following admission (Aquino 1997), or when there is evidence that neutropenia resolution is imminent (Bash 1994). More recent studies have shown this to be true even in children not

Early discontinuation of antibiotics for febrile neutropenia versus continuation until neutropenia resolution in people with cancer 17 (Review) 
meeting these criteria, but who were deemed clinically stable by their treating clinicians (Hodgson-Viden 2005; Lehrnbecher 2002). Similarly, in adult patients, two observational studies have shown that in haematologic neutropenic patients with fever of unexplained origin, discontinuation of antibiotics during neutropenia is safe (Cornelissen 1995; Slobbe 2009). To note, in these two studies, following discontinuation of broad-spectrum empiric antibiotic treatment, participants resumed antibacterial prophylaxis with fluoroquinolones. After reviewing the data from these studies and with the aim of reducing antibiotic usage in an era of growing resistance among haemato-oncologic patients, the Fourth European Conference on Infections in Leukemia (ECIL-4) guidelines for empirical antibacterial therapy for febrile neutropenic patients concluded that empirical antibiotics can be discontinued after 72 hours or more of intravenous administration in patients who are haemodynamically stable and have been afebrile for 48 hours or more, irrespective of neutrophil count or expected duration of neutropenia (Averbuch 2013a; Averbuch 2013b).

While observational studies all point to the safety of early antibiotic discontinuation, the RCTs raise some concerns due to the higher incidence of bacteraemia and documented infections among patients in whom antibiotics were stopped before neutropenia resolution and the lack of confidence in the outcome of mortality. The potential for selection bias in observational studies comparing patients in whom antibiotics were stopped early versus those continuing antibiotics is clear. While more pragmatic and less restrictive with respect to patient inclusion, observational studies cannot replace RCTs for the question of antibiotic treatment duration.

\section{AUTHORS' CONCLUSIONS}

\section{Implications for practice}

The relative paucity of data, variability of the included trials, and low certainty of the evidence preclude strong conclusions on the safety of antibiotic discontinuation before neutropenia resolution among patients with febrile neutropenia. By showing no difference in mortality and clinical failure, our review can be used to support the implementation of existing guidelines which allow for the discontinuation of antibiotics in stable patients disregarding their neutrophil count. In patients at high risk of bacteraemia, antibiotic discontinuation should be considered on an individual basis.

\section{Implications for research}

Our main conclusion is that well-designed, adequately powered randomised controlled trials (RCTs) are needed addressing the safety of stopping antibiotics before neutropenia resolution among high-risk haemato-oncological patients, separately for adults and children.

Based on the review of existing trials, the design features we deem important for such a trial include the following. The trial should include a homogenous patient population with febrile neutropenia, with all patients fulfilling clear criteria for antibiotic initiation. We believe that recruitment and randomisation should occur at the time point of planned antibiotic discontinuation to avoid the need to exclude patients with documented or suspected bacterial microbiologically documented infections and clinically documented infections and to minimise the potential for selection bias. A prospective consent to participate in the study when febrile neutropenia develops can possibly be sought from patients at the time of admission to streamline recruitment and allow inclusion of a more representative sample of patients, since at the time of febrile neutropenia patients may not be well enough to provide informed consent. Patients should be included only once into the trial. All-cause mortality should be assessed. Basing the sample size calculation on antibiotic treatment days, an indirect outcome measure, will lead to the lack of power for assessment of clinical patient-relevant outcomes. The sample size can be performed on a hierarchical outcome or using the Desirability of Outcome Ranking (DOOR) strategy, addressing survival and patients' well-being, to achieve a meaningful and feasible sample size (Evans 2015). In such an RCT, we would expect to see an evaluation of resistance selection or development through clinical assessment of infections caused by multidrug-resistant bacteria and surveillance of colonisation by multidrug-resistant bacteria.

In summary, existing RCTs cannot provide clear evidence that policies for early antibiotic discontinuation in febrile neutropenia are associated with fewer fungal infections, Clostridium difficile or secondary infections caused by resistant bacteria. Early antibiotic discontinuation in febrile neutropenia of unknown origin may be associated with higher rates of bacteraemia and documented infections, but this does not appear to translate to higher clinical failure rates or worse survival. In an era of pan-resistant bacteria among neutropenic cancer patients, more efforts should be invested in research defining the optimal duration of antibiotics in specific patient groups.

\section{ACK N OWLEDGEMENTS}

We thank Robin Grant for clinical and editorial advice; Jo Platt for designing the search strategy; and Gail Quinn and Tracey Harrison for their contribution to the editorial process.

This project was supported by the National Institute for Health Research (NIHR), via Cochrane Infrastructure funding to the Cochrane Gynaecological, Neuro-oncology and Orphan Cancer Group. The views and opinions expressed therein are those of the authors and do not necessarily reflect those of the Systematic Reviews Programme, NIHR, National Health Service (NHS), or the Department of Health.

We would like to thank the referees for many helpful suggestions and comments, including Helen Bulbeck, Andrew Byrant, Murat Akova, and Katharine Abba. 


\section{R E F E R E N C E S}

\section{References to studies included in this review}

Aguilar-Guisado 2017 \{published and unpublished data\}

Aguilar-Guisado M, Espigado I, Martín-Peña A, Gudiol C, Falantes J, Vázquez L, et al. Empirical antimicrobial therapy withdrawal after 72 hours of apyrexia in hematological patients with febrile neutropenia is safe and reduce unnecessary antibotic exposure: final results of randomized clinical trial "How Long". ECCMID proceeding. 2017 April.

\section{Bjornsson 1977 \{published data only\}}

Björnsson S, Preisler H, Henderson ES. A study of antibiotic therapy in fever of unknown origin in neutropenic cancer patients. Medical and Pediatric Oncology 1977;3(4):379-85.

Klaassen 2000a \{published data only\}

Klaassen RJ, Allen U, Doyle JJ. Randomized placebo-controlled trial of oral antibiotics in pediatric oncology patients at low-risk with fever and neutropenia. Journal of Pediatric Hematology/ Oncology 2000;22(5):405-11.

\section{Pizzo 1979 \{published data only\}}

Pizzo PA, Robichaud KJ, Gill FA, Witebsky FG, Levine AS, Deisseroth $A B$, et al. Duration of empiric antibiotic therapy in granulocytopenic patients with cancer. American Journal of Medicine 1979;67(2):194-200.

\section{Pizzo 1982 \{published data only\}}

Pizzo PA, Robichaud KJ, Gill FA, Witebsky FG. Empiric antibiotic and antifungal therapy for cancer patients with prolonged fever and granulocytopenia. American Journal of Medicine 1982;72(1):101-11.

\section{Rodriguez 1973 \{published data only\}}

Rodriguez V, Burgess M, Bodey GP. Management of fever of unknown origin in patients with neoplasms and neutropenia. Cancer 1973;32(4):1007-12.

\section{Santolaya 1997 \{published data only\}}

Santolaya ME, Villarroel M, Avendaño LF, Cofré J. Discontinuation of antimicrobial therapy for febrile, neutropenic children with cancer: a prospective study. Clinical Infectious Diseases 1997;25(1):92-7.

\section{Santolaya 2017 \{published data only\}}

Santolaya ME, Alvarez AM, Acuña M, Avilés CL, Salgado C, Tordecilla, et al. Efficacy and safety of withholding antimicrobial treatment in children with cancer, fever and neutropenia, with a demonstrated viral respiratory infection: a randomized clinical trial. Clinical Microbiology and Infection 2017;23(3):173-8.

\section{References to studies excluded from this review}

\section{Aoun 1998 \{published data only\}}

Aoun M, Crokaert F, Paesmans M, Autier P, Klastersky J. Imipenem versus targeted therapy in cancer patients. International Journal of Antimicrobial Agents 1998;10(4):263-70. [PUBMED: 9916899]
Aquino 1997 \{published data only\}

Aquino VM, Buchanan GR, Tkaczewski I, Mustafa MM. Safety of early hospital discharge of selected febrile children and adolescents with cancer with prolonged neutropenia. Medical and Pediatric Oncology 1997;28(3):191-5. [PUBMED: 9024515]

\section{Calandra 1987 \{published data only\}}

Calandra T, Klastersky J, Gaya H, Glauser MP, Meunier F, Zinner SH. Ceftazidime combined with a short or long course of amikacin for empirical therapy of gram-negative bacteremia in cancer patients with granulocytopenia. New England Journal of Medicine 1987;317(27):1692-8. [PUBMED: 2892130]

\section{Cherif 2004 \{published data only\}}

Cherif $\mathrm{H}$, Bjorkholm $\mathrm{M}$, Engervall $\mathrm{P}$, Johansson $\mathrm{P}$, Ljungman $\mathrm{P}$, Hast $R$, et al. A prospective, randomized study comparing cefepime and imipenem-cilastatin in the empirical treatment of febrile neutropenia in patients treated for haematological malignancies. Scandinavian Journal of Infectious Diseases 2004;36(8):593-600. [PUBMED: 15370671]

\section{Cohen 1995 \{published data only\}}

Cohen KJ, Leamer K, Odom L, Greffe B, Stork L. Cessation of antibiotics regardless of ANC is safe in children with febrile neutropenia. A preliminary prospective trial. Journal of Pediatric Hematology/Oncology 1995;17(4):325-30. [PUBMED: 7583388]

\section{Horowitz 1996 \{published data only\}}

Horowitz HW, Holmgren D, Seiter K. Stepdown single agent antibiotic therapy for the management of the high risk neutropenic adult with hematologic malignancies. Leukemia \& Lymphoma 1996;23(1-2):159-63. [PUBMED: 9021700]

\section{Idelevich 2015 \{published data only\}}

Idelevich EA, Silling G, Niederbracht Y, Penner H, Sauerland MC, Tafelski S, et al. Impact of multiplex PCR on antimicrobial treatment in febrile neutropenia: a randomized controlled study. Medical Microbiology and Immunology 2015;204(5):585-92. [PUBMED: 25573349]

Lee 1998 \{published data only\}

Lee JS, Lim YT. The effect of empirical antibiotics in febrile neutropenia. Journal of Korean Pediatric Society 1998;41(9):1209-15.

\section{Lima 2016 \{published data only\}}

Lima SS, Nobre V, de Castro Romanelli RM, Clemente WT, da Silva Bittencourt HN, Melo AC, et al. Procalcitoninguided protocol is not useful to manage antibiotic therapy in febrile neutropenia: a randomized controlled trial. Annals of Hematology 2016;95(7):1169-76. [PUBMED: 27118539]

\section{Pegram 1989 \{published data only\}}

Pegram PS, Phair JP, McMahan R, Murphy RL, Gordon LI, Washton $\mathrm{H}$, et al. Prospective comparative trial of short course (four day) and continuous tobramycin in combination with cefoperazone or mezlocillin in febrile,

Early discontinuation of antibiotics for febrile neutropenia versus continuation until neutropenia resolution in people with cancer 
granulocytopenic patients. Journal of Antimicrobial Chemotherapy 1989;24(4):591-604. [PUBMED: 2693432]

\section{Additional references}

\section{Andria 2015}

Andria N, Henig O, Kotler O, Domchenko A, Oren I, Zuckerman T, et al. Mortality burden related to infection with carbapenemresistant Gram-negative bacteria among haematological cancer patients: a retrospective cohort study. Journal of Antimicrobial Chemotherapy 2015;70(11):3146-53.

\section{Apostolopoulou 2011}

Apostolopoulou E, Raftopoulos V, Terzis K, Elefsiniotis I. Infection Probability Score: a predictor of Clostridium difficileassociated disease onset in patients with haematological malignancy. European Journal of Oncology Nursing 2011;15(5):404-9.

\section{Averbuch 2013a}

Averbuch D, Orasch C, Cordonnier C, Livermore DM, Mikulska M, Viscoli C, et al. a joint venture of EBMT, EORTC, ICHS, ESGICH/ ESCMID, ELN. European guidelines for empirical antibacterial therapy for febrile neutropenic patients in the era of growing resistance: summary of the 2011 4th European Conference on Infections in Leukemia. Haematologica 2013;98(12):1826-35.

\section{Averbuch 2013b}

Averbuch D, Cordonnier C, Livermore DM, Mikulska M, Orasch C, Viscoli C, et al. a joint venture of EBMT, EORTC, ICHS, ESGICH/ ESCMID, ELN. Targeted therapy against multi-resistant bacteria in leukemic and hematopoietic stem cell transplant recipients: guidelines of the 4th European Conference on Infections in Leukemia (ECIL-4, 2011). Haematologica 2013;98(12):1836-47.

\section{Barloon 1991}

Barloon TJ, Galvin JR, Mori M, Stanford W, Gingrich RD. Highresolution ultrafast chest $\mathrm{CT}$ in the clinical management of febrile bone marrow transplant patients with normal or nonspecific chest roentgenograms. Chest 1991;99(4):928-33.

\section{Bash 1994}

Bash RO, Katz JA, Cash JV, Buchanan GR. Safety and cost effectiveness of early hospital discharge of lower risk children with cancer admitted for fever and neutropenia. Cancer 1994;74(1):189-96. [PUBMED: 8004575]

\section{Bodey 2000}

Bodey GP. Unusual presentations of infection in neutropenic patients. International Journal of Antimicrobial Agents 2000;16(2):93-5.

\section{Bow 2013}

Bow EJ. Infection in neutropenic patients with cancer. Critical Care Clinics 2013;29(3):411-41.

\section{Cohen 2011}

Cohen J, Drage S. How I manage haematology patients with septic shock. British Journal of Haematology 2011;152(4):380-91. [PUBMED: 21210777]

\section{Cornelissen 1995}

Cornelissen JJ, Rozenberg-Arska M, Dekker AW. Discontinuation of intravenous antibiotic therapy during persistent neutropenia in patients receiving prophylaxis with oral ciprofloxacin. Clinical Infectious Diseases: an official publication of the Infectious Diseases Society of America 1995;21(5):1300-2. [PUBMED: 8589161]

\section{de Naurois 2010}

de Naurois J, Novitzky-Basso I, Gill MJ, Marti FM, Cullen MH, Roila F, ESMO Guidelines Working Group. Management of febrile neutropenia: ESMO Clinical Practice Guidelines. Annals of Oncology 2010;21(Suppl 5):v252-6.

\section{Evans 2015}

Evans SR, Rubin D, Follmann D, Pennello G, Huskins WC, Powers JH, et al. Desirability of Outcome Ranking (DOOR) and Response Adjusted for Duration of Antibiotic Risk (RADAR). Clinical Infectious Diseases: an official publication of the Infectious Diseases Society of America 2015;61(5):800-6. [PUBMED: 26113652]

\section{Freifeld 2011}

Freifeld AG, Bow EJ, Sepkowitz KA, Boeckh MJ, Ito JI, Mullen CA, et al. Clinical practice guideline for the use of antimicrobial agents in neutropenic patients with cancer: 2010 update by the Infectious Diseases Society of America. Clinical Infectious Diseases 2011;52(4):e56-93.

\section{Gudiol 2011}

Gudiol C, Tubau F, Calatayud L, Garcia-Vidal C, Cisnal M, Sánchez-Ortega I, et al. Bacteraemia due to multidrug-resistant Gram-negative bacilli in cancer patients: risk factors, antibiotic therapy and outcomes. Journal of Antimicrobial Chemotherapy 2011;66(3):657-63.

\section{Gustinetti 2016}

Gustinetti G, Mikulska M. Bloodstream infections in neutropenic cancer patients: a practical update. Virulence 2016;7(3):280-97. [PUBMED: 27002635]

\section{Higgins 2011}

Higgins JPT, Green S (editors). Cochrane Handbook for Systematic Reviews of Interventions Version 5.1.0 [updated March 2011]. The Cochrane Collaboration, 2011. Available from handbook.cochrane.org.

\section{Hodgson-Viden 2005}

Hodgson-Viden H, Grundy PE, Robinson JL. Early discontinuation of intravenous antimicrobial therapy in pediatric oncology patients with febrile neutropenia. $B M C$ Pediatrics 2005;5(1):10. [PUBMED: 15904510]

\section{Immunocompromised Host Society 1990}

From the Immunocompromised Host Society. The design, analysis, and reporting of clinical trials on the empirical antibiotic management of the neutropenic patient. Report of a consensus panel. Journal of Infectious Diseases 1990;161(3):397-401. 


\section{Klaassen 2000b}

Klaassen RJ, Goodman TR, Pham B, Doyle JJ. "Low-risk" prediction rule for pediatric oncology patients presenting with fever and neutropenia. Journal of Clinical Oncology 2000;18(5):1012-9.

\section{Klastersky 2000}

Klastersky J, Paesmans M, Rubenstein EB, Boyer M, Elting L, Feld R, et al. The Multinational Association for Supportive Care in Cancer risk index: a multinational scoring system for identifying low-risk febrile neutropenic cancer patients. Journal of Clinical Oncology 2000;18(16):3038-51.

\section{Klastersky 2004}

Klastersky J. Management of fever in neutropenic patients with different risks of complications. Clinical Infectious Diseases 2004;39 Suppl 1:S32-7.

\section{Krcmery 1998}

Krcmery V Jr, Oravcova E, Spanik S, Mrazova-Studena M, Trupl J, Kunova A, et al. Nosocomial breakthrough fungaemia during antifungal prophylaxis or empirical antifungal therapy in 41 cancer patients receiving antineoplastic chemotherapy: analysis of aetiology risk factors and outcome. Journal of Antimicrobial Chemotherapy 1998;41(3):373-80.

\section{Lehrnbecher 2002}

Lehrnbecher T, Stanescu A, Kuhl J. Short courses of intravenous empirical antibiotic treatment in selected febrile neutropenic children with cancer. Infection 2002;30(1):17-21. [PUBMED: 11876510]

\section{Li 2014}

Li Y, Xu W, Jiang Z, Gao Y, Pang Y, Li L, et al. Neutropenia and invasive fungal infection in patients with hematological malignancies treated with chemotherapy: a multicenter, prospective, non-interventional study in China. Tumour Biology 2014;35(6):5869-76.

\section{Lingaratnam 2011}

Lingaratnam S, Slavin MA, Koczwara B, Seymour JF, Szer J, Underhill C, et al. Australian Consensus Guidelines 2011 Steering Committee. Introduction to the Australian consensus guidelines for the management of neutropenic fever in adult cancer patients. Internal Medicine Journal 2011;41(1b):75-81.

\section{Masaoka 2004}

Masaoka T. Evidence-based recommendations for antimicrobial use in febrile neutropenia in Japan: executive summary. Clinical Infectious Diseases 2004;39(Suppl 1):S49-52.

\section{Ohmagari 2005}

Ohmagari N, Hanna H, Graviss L, Hackett B, Perego C, Gonzalez V, et al. Risk factors for infections with multidrugresistant Pseudomonas aeruginosa in patients with cancer. Cancer 2005;104(1):205-12.

\section{Oude Nijhuis 2003}

Oude Nijhuis CS, Gietema JA, Vellenga E, Daenen SM, De Bont ES, Kamps WA, et al. Routine radiography does not have a role in the diagnostic evaluation of ambulatory adult febrile neutropenic cancer patients. European Journal of Cancer 2003;39(17):2495-8.

\section{Penack 2014}

Penack O, Becker C, Buchheidt D, Christopeit M, Kiehl M, von Lilienfeld-Toal $M$, et al. Management of sepsis in neutropenic patients: 2014 updated guidelines from the Infectious Diseases Working Party of the German Society of Hematology and Medical Oncology (AGIHO). Annals of Hematology 2014;93(7):1083-95.

\section{Phillips 2012}

Phillips R, Hancock B, Graham J, Bromham N, Jin H, Berendse S. Prevention and management of neutropenic sepsis in patients with cancer: summary of NICE guidance. BMJ 2012;345:e5368.

\section{Pizzo 1993}

Pizzo PA. Management of fever in patients with cancer and treatment-induced neutropenia. New England Journal of Medicine 1993;328(18):1323-32.

\section{Ram 2012}

Ram R, Farbman L, Leibovici L, Raanani P, Yeshurun M, Vidal L, et al. Characteristics of initial compared with subsequent bacterial infections among hospitalised haemato-oncological patients. International Journal of Antimicrobial Agents 2012;40(2):123-6.

\section{RevMan 2014 [Computer program]}

The Nordic Cochrane Centre, The Cochrane Collaboration. Review Manager (RevMan). Version 5.3. Copenhagen: The Nordic Cochrane Centre, The Cochrane Collaboration, 2014.

\section{Righi 2017}

Righi E, Peri AM, Harris PN, Wailan AM, Liborio M, Lane SW, et al. Global prevalence of carbapenem resistance in neutropenic patients and association with mortality and carbapenem use: systematic review and meta-analysis. Journal of Antimicrobial Chemotherapy 2017;72(3):668-77. [PUBMED: 27999023]

\section{Schalk 2010}

Schalk E, Bohr UR, König B, Scheinpflug K, Mohren M. Clostridium difficile-associated diarrhoea, a frequent complication in patients with acute myeloid leukaemia. Annals of Hematology 2010;89(1):9-14.

\section{Schimpff 1971}

Schimpff S, Satterlee W, Young VM, Serpick A. Empiric therapy with carbenicillin and gentamicin for febrile patients with cancer and granulocytopenia. New England Journal of Medicine 1971;284(19):1061-5.

\section{Sickles 1975}

Sickles EA, Greene WH, Wiernik PH. Clinical presentation of infection in granulocytopenic patients. Archives of Internal Medicine 1975;135(5):715-9.

\section{Singh 2001}

Singh N. Trends in the epidemiology of opportunistic fungal infections: predisposing factors and the impact of antimicrobial use practices. Clinical Infectious Diseases 2001;33(10):1692-6.

Early discontinuation of antibiotics for febrile neutropenia versus continuation until neutropenia resolution in people with cancer 


\section{Slobbe 2009}

Slobbe L, Waal Lv, Jongman LR, Lugtenburg PJ, Rijnders BJ. Three-day treatment with imipenem for unexplained fever during prolonged neutropaenia in haematology patients receiving fluoroquinolone and fluconazole prophylaxis: a prospective observational safety study. European Journal of Cancer (Oxford, England: 1990) 2009;45(16):2810-7. [PUBMED: 19647995]

\section{Sterne 2001}

Sterne JAC, Egger M. Funnel plots for detecting bias in metaanalysis: guidelines on choice of axis. Journal of Clinical Epidemiology 2001;54(10):1046-55.

\section{Talcott 1992}

Talcott JA, Siegel RD, Finberg R, Goldman L. Risk assessment in cancer patients with fever and neutropenia: a prospective, two-center validation of a prediction rule. Journal of Clinical Oncology 1992;10(2):316-22.

\section{Vidal 2013}

Vidal L, Ben Dor I, Paul M, Eliakim-Raz N, Pokroy E, SoaresWeiser K, et al. Oral versus intravenous antibiotic treatment for febrile neutropenia in cancer patients. Cochrane

\section{CHARACTERISTICS OF STUDIES}

Characteristics of included studies [ordered by study ID]
Database of Systematic Reviews 2013, Issue 10. [DOI: 10.1002/14651858.CD003992.pub3]

\section{Viscoli 2002}

Viscoli C, EORTC International Antimicrobial Therapy Group. Management of infection in cancer patients: studies of the EORTC International Antimicrobial Therapy Group (IATG). European Journal of Cancer 2002;38(Suppl 4):S82-7.

\section{Wan 2014}

Wan X, Wang W, Liu J, Tong T. Estimating the sample mean and standard deviation from the sample size, median, range and/or interquartile range. BMC Medical Research Methodology 2014;14:135.

\section{White 2014}

White L, Ybarra M. Neutropenic fever. Emergency Medicine Clinics of North America 2014;32(3):549-61.

\section{Wood 2008}

Wood L, Egger M, Gluud LL, Schulz KF, Jüni P, Altman DG, et al. Empirical evidence of bias in treatment effect estimates in controlled trials with different interventions and outcomes: meta-epidemiological study. BMJ 2008;336(7644):601-5.

Aguilar-Guisado 2017

Methods Study design: randomised, open-label trial

Study duration: April 2012 to May 2016

Inclusion criteria
Participants
- Setting: 6 centres
- Country: Spain
tropenia and fever
- Number: short-therapy arm (78); long-therapy arm (79). Total randomised = 157 participants
- Median age (IQR):
* Short-therapy arm: 52 years (42 to 61$)$

$*$ Long-therapy arm: 54 years (39 to 63$)$

\section{Exclusion criteria}

- Aetiological diagnosis of neutropenic fever

- HIV infection

- Pregnancy or breastfeeding

- Renal failure

- Concomitant therapy with cytochrome P450 3A4 (CYP3A4) substratum

- Epilepsy

- Prior antibiotic therapy

Evaluation of participants versus episodes: participant data reported

Definition of fever: not provided 
Aguilar-Guisado 2017 (Continued)

Definition of neutropenia: ANC $<500 / \mu \mathrm{L}$

Expected neutropenia duration: $>7$ days

- Antibiotic therapy before randomisation: antipseudomonal beta-lactam as monotherapy or combi-
nation according to international guidelines
- Day start (day of randomisation): 72 hours after fever onset
- Management after randomisation:
- Short-therapy arm: antibiotic therapy stopped if apyrexia + signs and symptoms resolution + nor-
mal vital signs
- Long-therapy arm: continuation of the same regimen
Planned duration of antibiotic treatment:
$*$ Short-therapy arm: until apyrexia + signs and symptoms resolution + normal vital signs
$*$ Long-therapy arm: until apyrexia + signs and symptoms resolution + normal vital signs + ANC $>$
- Follow-up: 28 days

Outcomes Primary outcome: number of days on which participant is free of antimicrobial treatment

Mortality outcome definition: crude mortality at 28 days

Other relevant outcomes:

- Clinical failure: defined as recurrent fever

- Number of fever days from randomisation

- Total antibiotic days from randomisation

- Any documented infection after randomisation

- Any fungal infection after randomisation

- Development of Clostridium difficile-associated diarrhoea

Full agreement between outcomes in registry versus results: yes

Full agreement between outcomes in methods versus results: yes

Notes $\quad$ Funding source: Fundación Pública Andaluza para la gestión de la Investigación en Sevilla

\section{Risk of bias}

\begin{tabular}{lll}
\hline Bias & Authors' judgement & Support for judgement \\
\hline $\begin{array}{l}\text { Random sequence genera- } \\
\text { tion (selection bias) }\end{array}$ & Low risk & Random-number generator \\
\hline $\begin{array}{l}\text { Allocation concealment } \\
\text { (selection bias) }\end{array}$ & Low risk & Central randomisation \\
\hline $\begin{array}{l}\text { Blinding of participants } \\
\text { and personnel (perfor- } \\
\text { mance bias) }\end{array}$ & High risk & No blinding \\
All outcomes & & \\
\hline
\end{tabular}

$\begin{array}{lll}\text { Blinding of outcome as- } & \text { High risk } & \text { No blinding } \\ \text { sessment (detection bias) } & \end{array}$

All outcomes

Incomplete outcome data Low risk ITT and per-protocol data provided.

(attrition bias)

All outcomes

Early discontinuation of antibiotics for febrile neutropenia versus continuation until neutropenia resolution in people with cancer 
Aguilar-Guisado 2017 (Continued)

Selective reporting (re- Low risk $\quad$ Full agreement between outcomes in registry and those in publication porting bias)

Other bias Low risk Sample size calculation with no early stop

Bjornsson 1977

Methods Study design: randomised, open-label trial

Study duration: June 1975 to May 1976

\section{Participants}

\section{Inclusion criteria}

- Setting: 1 centre

- Country: USA

- Health status: adult patients with neutropenia and fever of unknown origin with non-resolving fever after 3 days of antibiotic treatment

- Number: short-therapy arm (6); long-therapy arms: chloramphenicol arm (6), clindamycin arm (5). Total randomised $=17$ participants

- Mean age (SD):

* Short-therapy arm: 42.5 years $( \pm 11.8)$

* Long-therapy arm: 43.45 years $( \pm 16.5)$

\section{Exclusion criteria}

- Exposure to antibiotics during the 2 or more days preceding the fever

- Any focus of infection or isolation of pathogen

Evaluation of participants versus episodes: episodes data collected, but outcome data reported per participant

Definition of fever: temperature of $38^{\circ} \mathrm{C}$ or higher that is not related to transfusion reaction

Definition of neutropenia: granulocyte count $<500 / \mu \mathrm{L}$

Expected neutropenia duration: not restricted

Interventions

- Antibiotic therapy before randomisation: IV carbenicillin $500 \mathrm{mg} / \mathrm{kg} / \mathrm{d}+\mathrm{IV}$ cephalothin $150 \mathrm{mg} / \mathrm{kg} / \mathrm{d}$ + IV gentamicin $5 \mathrm{mg} / \mathrm{kg} / \mathrm{d}$

- Day start (day of randomisation): after 3 days of antibiotic therapy

- Management after randomisation:

- Short-therapy arm: no antibiotics

- Long-therapy arm:

* Chloramphenicol arm: IV carbenicillin 500 mg/kg/d + IV cephalothin 150 mg/kg/d + IV gentamicin $5 \mathrm{mg} / \mathrm{kg} / \mathrm{d}+$ IV chloramphenicol $50 \mathrm{mg} / \mathrm{kg} / \mathrm{d}$

* Clindamycin arm: IV carbenicillin $500 \mathrm{mg} / \mathrm{kg} / \mathrm{d}$ + IV cephalothin $150 \mathrm{mg} / \mathrm{kg} / \mathrm{d}$ + IV gentamicin 5 $\mathrm{mg} / \mathrm{kg} / \mathrm{d}+$ IV clindamycin $30 \mathrm{mg} / \mathrm{kg} / \mathrm{d}$

- Planned duration of antibiotic treatment:

- * Short-therapy arm: 3 days (stopped at randomisation)

* Long-therapy arm: 10 days (continued 7 days after randomisation)

- Follow-up: 4 weeks

Outcomes

Primary outcome: resolution of fever and return of signs and symptoms to pre-fever state

Mortality outcome definition: all-cause mortality at 4 weeks

Early discontinuation of antibiotics for febrile neutropenia versus continuation until neutropenia resolution in people with cancer (Review)

Copyright (C) 2019 The Cochrane Collaboration. Published by John Wiley \& Sons, Ltd. 
Bjornsson 1977 (Continued)

Other relevant outcomes:

- Any bacteraemia after randomisation

- Any documented infection after randomisation

- Any fungal infection after randomisation

Full agreement between outcomes in registry versus results: no registry

Full agreement between outcomes in methods versus results: no (outcomes not clearly defined in methods)

\begin{tabular}{ll}
\hline Notes & Funding source: academic \\
- & All patients with fever and neutropenia were included, but only patients with un resolving fever were \\
& randomised. All patients whose fever responded to antibiotic treatment continued therapy.
\end{tabular}

\section{Risk of bias}

\begin{tabular}{|c|c|c|}
\hline Bias & Authors' judgement & Support for judgement \\
\hline $\begin{array}{l}\text { Random sequence genera- } \\
\text { tion (selection bias) }\end{array}$ & Unclear risk & Not specified \\
\hline $\begin{array}{l}\text { Allocation concealment } \\
\text { (selection bias) }\end{array}$ & Unclear risk & Not specified \\
\hline $\begin{array}{l}\text { Blinding of participants } \\
\text { and personnel (perfor- } \\
\text { mance bias) } \\
\text { All outcomes }\end{array}$ & High risk & No blinding \\
\hline $\begin{array}{l}\text { Blinding of outcome as- } \\
\text { sessment (detection bias) } \\
\text { All outcomes }\end{array}$ & High risk & No blinding \\
\hline $\begin{array}{l}\text { Incomplete outcome data } \\
\text { (attrition bias) } \\
\text { All outcomes }\end{array}$ & Low risk & No post randomisation dropouts \\
\hline $\begin{array}{l}\text { Selective reporting (re- } \\
\text { porting bias) }\end{array}$ & High risk & No registry, outcomes not defined in methods \\
\hline Other bias & Unclear risk & No sample size calculation. No report on early stop \\
\hline
\end{tabular}

\section{Klaassen 2000a}

\begin{tabular}{ll} 
Methods & Study design: randomised, double-blind, placebo-controlled trial \\
& Study duration: August 1996 to April 1998 \\
\hline Participants & Inclusion criteria \\
- Setting: 1 centre & Country: Canada \\
- Health status: children with low-risk neutropenia and fever \\
- Number: short-therapy arm (36); long-therapy arm (37). Total randomised $=73$ episodes in 54 partic- \\
ipants
\end{tabular}


Klaassen 2000a (Continued)

- Mean age (SD):

* Short-therapy arm: 4.3 years (NA)

* Long-therapy arm: 4.9 years (NA)

\section{Exclusion criteria}

- Allergy to penicillin or cephalosporin antibiotics

- Any bacteraemia

- Any localised infection necessitating antibiotic therapy

- Fever for more than 96 hours after starting IV antibiotics

- Inability to tolerate oral medications

- Underlying cancer not in bone marrow remission

- Comorbid conditions necessitating continued inpatient stay

Evaluation of participants versus episodes: episode data reported

Definition of fever: oral or equivalent temperature $>38.5^{\circ} \mathrm{C}$ once or $>38^{\circ} \mathrm{C}$ on 2 or more occasions during a 12-hour period

Definition of neutropenia: ANC $<500 / \mu \mathrm{L}$

Expected neutropenia duration: not restricted

Interventions

- Antibiotic therapy before randomisation: IV piperacillin $50 \mathrm{mg} / \mathrm{kg}$ per dose every 6 hours and IV gentamicin $2.5 \mathrm{mg} / \mathrm{kg}$ per dose every 8 hours, or a similar combination. Other antibiotics may have been administered in addition if there was a suspicion of a localised infection.

- Day start (day of randomisation): 48 to 120 hours after admission

- Management after randomisation

- Short-therapy arm: placebo

- Long-therapy arm: oral cloxacillin syrup or capsules 75 to $100 \mathrm{mg} / \mathrm{kg}$ per day, 4 times daily + oral cefixime syrup $8 \mathrm{mg} / \mathrm{kg}$ per day, 1 dose daily

- Planned duration of antibiotic treatment:

- * Short-therapy arm: 48 to 120 hours followed by placebo until 14 days or ANC $>500 / \mu \mathrm{L}$

* Long-therapy arm: 14 days or until ANC $>500 / \mu \mathrm{L}$

- Follow-up: until ANC recovery

Outcomes

Primary outcome: recurrence of fever or newly documented bacterial infection before neutrophil recovery

Mortality outcome definition: death during neutropenia

Other relevant outcomes:

- Clinical failure: defined as readmission while still neutropenic

- Any bacteraemia after randomisation

Full agreement between outcomes in registry versus results: no registry

Full agreement between outcomes in methods versus results: yes

Notes Rhone-Poulenc Rorer Canada Inc. and Apotex Inc. supplied the antibiotics and placebos.

\section{Risk of bias}

\begin{tabular}{lll}
\hline Bias & Authors' judgement & Support for judgement \\
\hline $\begin{array}{l}\text { Random sequence genera- } \\
\text { tion (selection bias) }\end{array}$ & Low risk & Computer-generated block randomisation list \\
\hline
\end{tabular}

Early discontinuation of antibiotics for febrile neutropenia versus continuation until neutropenia resolution in people with cancer 
Klaassen 2000a (Continued)

\begin{tabular}{lll}
$\begin{array}{l}\text { Allocation concealment } \\
\text { (selection bias) }\end{array}$ & Low risk & Randomisation done at pharmacy. \\
\hline $\begin{array}{l}\text { Blinding of participants } \\
\text { and personnel (perfor- } \\
\text { mance bias) }\end{array}$ & Low risk & Double-blind, placebo-controlled trial \\
All outcomes & &
\end{tabular}

Blinding of outcome as- Low risk $\quad$ Outcome assessors were blinded.

sessment (detection bias)

All outcomes

\begin{tabular}{lll}
\hline $\begin{array}{l}\text { Incomplete outcome data } \\
\text { (attrition bias) } \\
\text { All outcomes }\end{array}$ & Low risk & No post randomisation dropouts \\
\hline $\begin{array}{l}\text { Selective reporting (re- } \\
\text { porting bias) }\end{array}$ & Low risk & $\begin{array}{l}\text { No registry. Full agreement between outcomes in methods and those in re- } \\
\text { sults }\end{array}$ \\
\hline Other bias & Low risk & Sample size was calculated. No early stop \\
\hline
\end{tabular}

\section{Pizzo 1979}

\begin{tabular}{|c|c|}
\hline Methods & $\begin{array}{l}\text { Study design: randomised, open-label trial } \\
\text { Study duration: November } 1975 \text { to February } 1978\end{array}$ \\
\hline Participants & $\begin{array}{l}\text { Inclusion criteria } \\
\text { - Setting: } 1 \text { centre } \\
\text { - Country: USA } \\
\text { - Health status: adults and children with neutropenia and fever of unknown origin with resolving fever } \\
\text { after } 7 \text { days of antibiotic treatment } \\
\text { - Number: short-therapy arm (17); long-therapy arm: (16). Total randomised = } 33 \text { participants } \\
\text { - Median age (range): } \\
* \text { Short-therapy arm: } 14 \text { years ( } 2 \text { to } 33 \text { ) } \\
* \text { Long-therapy arm: } 15 \text { years ( } 1 \text { to } 30) \\
\text { Exclusion criteria } \\
\text { - Patients with documented infection } \\
\text { - Patients whose neutropenia resolved before randomisation } \\
\text { - Patients with persistent fever } \\
\text { Evaluation of participants versus episodes: episodes (number of participants not clear) } \\
\text { Definition of fever: oral temperature }>38^{\circ} \mathrm{C} \text { on } 3 \text { measurements during } 24 \text { hours or } \geq 38.5^{\circ} \mathrm{C} \text { on a single } \\
\text { measurement } \\
\text { Definition of neutropenia: ANC (polymorphonuclear cells + band forms) }<500 / \mu \mathrm{L} \\
\text { Expected neutropenia duration: not restricted }\end{array}$ \\
\hline
\end{tabular}

Interventions

- Antibiotic therapy before randomisation: cefalotin (Keflin) $(170 \mathrm{mg} / \mathrm{kg} / \mathrm{d}$, IV every 4 hours $)+$ gentamicin $(6 \mathrm{mg} / \mathrm{kg} / \mathrm{d}$, IV every 6 hours) + carindacillin ( $500 \mathrm{mg} / \mathrm{kg} / \mathrm{d}$, IV every 4 hours) 
Pizzo 1979 (Continued)

- Management after randomisation:

* Short-therapy arm: no antibiotics

* Long-therapy arm: continuation of the same regimen

- Day start (day of randomisation): day 7 from admission

- Planned duration:

* Short-therapy arm: 7 days

* Long-therapy arm: until afebrile for $\geq 24$ hours and ANC $>500$

- Follow-up: 30 days after fever and neutropenia resolution

Primary outcome: not defined
Mortality outcome definition: 30 days' all-cause mortality
Other relevant outcomes:
- Clinical failure: defined as recurrence of fever
- Any bacteraemia after randomisation
- Any documented infection after randomisation
- Any fungal infection after randomisation
- Surveillance for resistant pathogens
Full agreement between outcomes in registry versus results: no registry
Full agreement between outcomes in methods versus results: outcomes not defined in methods
Funding source: not specified
This the first of 2 publications of the same trial; this one included only cases of resolving fever, while the
second one, Pizzo 1982 , included only cases with non-resolving fever.

\section{Risk of bias}

\begin{tabular}{|c|c|c|}
\hline Bias & Authors' judgement & Support for judgement \\
\hline $\begin{array}{l}\text { Random sequence genera- } \\
\text { tion (selection bias) }\end{array}$ & Unclear risk & Not specified \\
\hline $\begin{array}{l}\text { Allocation concealment } \\
\text { (selection bias) }\end{array}$ & Unclear risk & Not specified \\
\hline $\begin{array}{l}\text { Blinding of participants } \\
\text { and personnel (perfor- } \\
\text { mance bias) } \\
\text { All outcomes }\end{array}$ & High risk & No blinding \\
\hline $\begin{array}{l}\text { Blinding of outcome as- } \\
\text { sessment (detection bias) } \\
\text { All outcomes }\end{array}$ & High risk & No blinding \\
\hline $\begin{array}{l}\text { Incomplete outcome data } \\
\text { (attrition bias) } \\
\text { All outcomes }\end{array}$ & Low risk & No post randomisation dropouts \\
\hline $\begin{array}{l}\text { Selective reporting (re- } \\
\text { porting bias) }\end{array}$ & High risk & No registry, outcomes not defined in methods \\
\hline Other bias & Unclear risk & No sample size calculation. No report on early stop \\
\hline
\end{tabular}

Early discontinuation of antibiotics for febrile neutropenia versus continuation until neutropenia resolution in people with cancer 


\section{Participants}

\section{Inclusion criteria}

- Setting: 1 centre

- Country: USA

- Health status: adults and children with neutropenia and fever of unknown origin with non-resolving fever after 7 days of antibiotic treatment

- Number: short-therapy arm (16); long-therapy arms: antibacterial arm (16), antibacterial + amphotericin B arm (18). Total randomised $=50$ participants

- Median age (range):

* Short-therapy arm: 15 years (2 to 22)

* Long-therapy arms:

$\square$ antibacterial arm: 16 years ( 2 to 25 )

$\square$ antibacterial + amphotericin B arm: 18 years (8 to 30 )

\section{Exclusion criteria}

- Patients with documented infection

- Patients whose neutropenia resolved before randomisation

- Patients with no fever at randomisation

Evaluation of participants versus episodes: episodes (number of participants not clear)

Definition of fever: oral temperature $>38^{\circ} \mathrm{C}$ on 3 measurements during 24 hours or $\geq 38.5^{\circ} \mathrm{C}$ on a single measurement

Definition of neutropenia: ANC (polymorphonuclear cells + band forms) $<500 / \mu \mathrm{L}$

Expected neutropenia duration: not restricted

Interventions

- Antibiotic therapy before randomisation: cefalotin (Keflin) $(170 \mathrm{mg} / \mathrm{kg} / \mathrm{d}$, IV every 4 hours) + gentamicin (6 mg/kg/d, IV every 6 hours) + carindacillin (500 mg/kg/d, IV every 4 hours)

- Management after randomisation:

* Short-therapy arm: no antibiotics

* Long-therapy arms:

$\square$ antibacterial arm: continuation of the same regimen

$\square$ antibacterial + amphotericin B arm: continuation of the same regimen + amphotericin B $(0.5$ $\mathrm{mg} / \mathrm{kg} / \mathrm{d}, \mathrm{IV}$ )

- Day start (day of randomisation): day 7 from admission

- Planned duration:

* Short-therapy arm: 7 days

* Long-therapy arms: until afebrile for $\geq 24$ hours and ANC $>500$

- Follow-up: until fever and neutropenia resolution

Outcomes

Primary outcome: not defined

Mortality outcome definition: during follow-up

Other relevant outcomes:

- Clinical failure: defined as any infectious complication

- Number of fever days from randomisation

- Any bacteraemia after randomisation

- Any documented infection after randomisation

Early discontinuation of antibiotics for febrile neutropenia versus continuation until neutropenia resolution in people with cancer 
Pizzo 1982 (Continued)

- Any fungal infection after randomisation

- Development of antibiotic resistance: defined as any isolation resistant to given antibiotic

Full agreement between outcomes in registry versus results: no registry

Full agreement between outcomes in methods versus results: outcomes not defined in methods

Notes Funding source: not specified

This the second of 2 publications of the same trial; this one included only cases of non-resolving fever, while the first one, Pizzo 1979, included only cases with resolving fever.

\section{Risk of bias}

\begin{tabular}{lll}
\hline Bias & Authors' judgement & Support for judgement \\
\hline $\begin{array}{l}\text { Random sequence genera- } \\
\text { tion (selection bias) }\end{array}$ & Unclear risk & Not specified \\
\hline $\begin{array}{l}\text { Allocation concealment } \\
\text { (selection bias) }\end{array}$ & Unclear risk & Not specified \\
\hline $\begin{array}{l}\text { Blinding of participants } \\
\text { and personnel (perfor- } \\
\text { mance bias) } \\
\text { All outcomes }\end{array}$ & High risk & No blinding \\
\hline
\end{tabular}

Blinding of outcome as- High risk No blinding

sessment (detection bias)

All outcomes

Incomplete outcome data Low risk No post randomisation dropouts
(attrition bias)
All outcomes

Selective reporting (re- High risk No registry, outcomes not defined in methods
porting bias)

Other bias Unclear risk No sample size calculation. No report on early stop

Rodriguez 1973

Methods Study design: randomised, open-label trial

Study duration: July 1970 to December 1971

\section{Participants}

\section{Inclusion criteria}

- Setting: 1 centre

- Country: USA

- Health status: adults and children older than 15 years with neutropenia and fever of unknown origin

- Number: short-therapy arms: non-resolving fever (11), resolving fever (30); long-therapy arms: nonresolving fever (14), resolving fever (26). Total randomised $=81$ participants

- Median age (range): 33 years (15 to 80 )

\section{Exclusion criteria}

Early discontinuation of antibiotics for febrile neutropenia versus continuation until neutropenia resolution in people with cancer 
Rodriguez 1973 (Continued)

- Patients with documented infection

Evaluation of participants versus episodes: episodes (number of participants reported)

Definition of fever: $101^{\circ} \mathrm{F}$ or greater, not related to transfusion of blood products. Patients with fever that persisted for more than 4 hours after transfusion were also eligible.

Definition of neutropenia: polymorphonuclear leukocytes $<1000 / \mathrm{mm}^{3}$

Expected neutropenia duration: not restricted

Interventions

- Antibiotic therapy before randomisation: carindacillin (IV, 5 g every 4 hours) + cefalotin (IV, 3 g every 6 hours)

- Management after randomisation:

* Short-therapy arms: no antibiotics

* Long-therapy arms: continuation of the same regimen

- Day start (day of randomisation): day 4 of antibiotic therapy

- Planned duration:

* Short-therapy arms: 4 days

* Long-therapy arms: 10 days of additional therapy (total 14 days) or 5 days after becoming afebrile, whichever was longer

- Follow-up: not specified

Outcomes Primary outcome: not defined

Mortality outcome definition: not defined (mortality reported only for participants with documented infection)

Other relevant outcomes:

- Clinical failure: defined as diagnosis of infection as cause of fever

- Any bacteraemia after randomisation (reported as bacterial sepsis)

- Any documented infection after randomisation

- Any fungal infection after randomisation

- Development of antibiotic resistance: defined as resistance to study antibiotics

Full agreement between outcomes in registry versus results: no registry

Full agreement between outcomes in methods versus results: outcomes not defined in methods

Notes Funding source: academic

Each study arm was divided into a non-resolving fever group and a resolving fever group.

\section{Risk of bias}

\begin{tabular}{lll}
\hline Bias & Authors' judgement & Support for judgement \\
\hline $\begin{array}{l}\text { Random sequence genera- } \\
\text { tion (selection bias) }\end{array}$ & Unclear risk & Not specified \\
\hline $\begin{array}{l}\text { Allocation concealment } \\
\text { (selection bias) }\end{array}$ & Unclear risk & Not specified \\
\hline $\begin{array}{l}\text { Blinding of participants } \\
\text { and personnel (perfor- } \\
\text { mance bias) }\end{array}$ & High risk & No blinding \\
All outcomes & \\
\hline
\end{tabular}

Early discontinuation of antibiotics for febrile neutropenia versus continuation until neutropenia resolution in people with cancer 
Rodriguez 1973 (Continued)

Blinding of outcome as- High risk No blinding sessment (detection bias)

All outcomes

Incomplete outcome data Low risk No post randomisation dropouts
(attrition bias)

All outcomes

Selective reporting (re- High risk No registry, outcomes not defined in methods

porting bias)

Other bias Unclear risk No sample size calculation. No report on early stop

Santolaya 1997

Methods Study design: randomised, double-blind, placebo-controlled trial

Study duration: January 1994 to January 1996

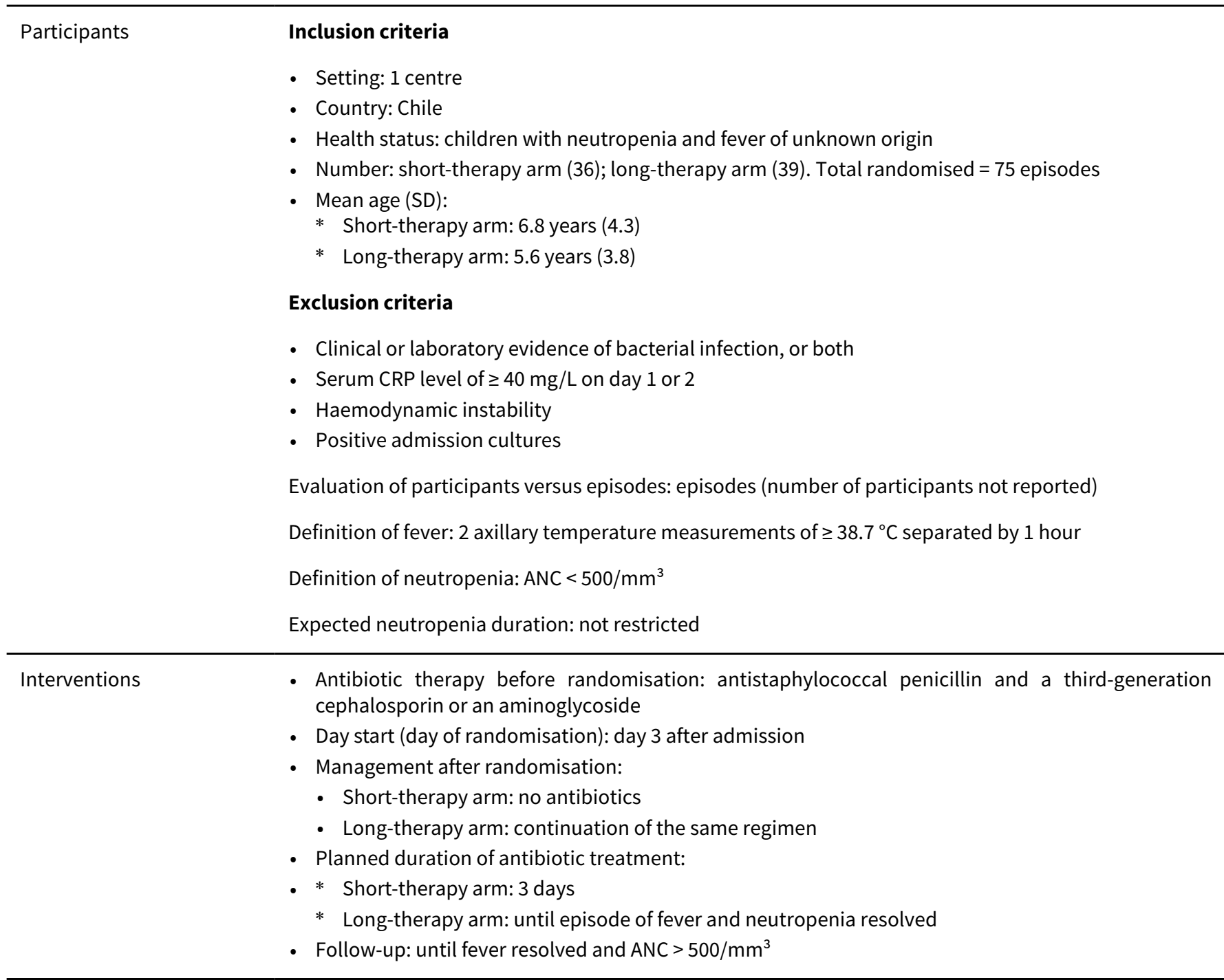

Early discontinuation of antibiotics for febrile neutropenia versus continuation until neutropenia resolution in people with cancer 
Santolaya 1997 (Continued)

Outcomes
Primary outcome: clinical failure defined as an unfavourable outcome (any of the following: detection of a clinical focus suggestive of a bacterial infection, a positive bacterial culture after day 3, reappearance of fever, deterioration of haemodynamic stability, or progressive increase in serum CRP levels to > 40 in 2 consecutive measurements)

Mortality outcome definition: in-hospital mortality

Other relevant outcomes:

- Number of fever days from randomisation

- Total antibiotic days from randomisation

- Any bacteraemia after randomisation

- Any documented infection after randomisation

- Development of antibiotic resistance: reported as cases of ESBL isolates

- Length of hospitalisation

Full agreement between outcomes in registry versus results: no registry

Full agreement between outcomes in methods versus results: no, more outcomes reported in results than in methods

Notes Funding source: not specified

\section{Risk of bias}

\begin{tabular}{lll}
\hline Bias & Authors' judgement & Support for judgement \\
\hline $\begin{array}{l}\text { Random sequence genera- } \\
\text { tion (selection bias) }\end{array}$ & Unclear risk & Not specified \\
\hline $\begin{array}{l}\text { Allocation concealment } \\
\text { (selection bias) }\end{array}$ & Unclear risk & Not specified \\
\hline $\begin{array}{l}\text { Blinding of participants } \\
\text { and personnel (perfor- } \\
\text { mance bias) } \\
\text { All outcomes }\end{array}$ & High risk & No blinding \\
\hline
\end{tabular}

Blinding of outcome as- High risk No blinding

sessment (detection bias)

All outcomes

Incomplete outcome data Low risk No post randomisation dropouts
(attrition bias)

All outcomes

Selective reporting (re- High risk No registry, more outcomes reported in results than in methods
porting bias)

Other bias Unclear risk No sample size calculation. No report on early stop

Santolaya 2017

Methods

Study design: randomised, open-label trial

Study duration: July 2012 to December 2015

Early discontinuation of antibiotics for febrile neutropenia versus continuation until neutropenia resolution in people with cancer (Review)

Copyright @ 2019 The Cochrane Collaboration. Published by John Wiley \& Sons, Ltd. 
Santolaya 2017 (Continued)

Participants

\section{Inclusion criteria}

- Setting: 5 centres

- Country: Chile

- Health status: children with fever and neutropenia and a nasopharyngeal sample positive for a respiratory virus

- Number: short-therapy arm (84); long-therapy arm (92). Total randomised = 176 participants

- Median age (IQR):

* Short-therapy arm: 4 years ( 3 to 8 )

* Long-therapy arm: 5 years ( 3 to 9 )

\section{Exclusion criteria}

- Haematopoietic stem cell transplantation

- Any documented bacterial infection

- Any clinical foci of infection

- Unfavourable evolution before randomisation (fever, $\mathrm{CRP} \geq 90 \mathrm{mg} / \mathrm{L}$, haemodynamic instability)

Evaluation of participants versus episodes: participant data reported (for each participant only first neutropenic fever episode included)

Definition of fever: single axillary temperature $\geq 38.5^{\circ} \mathrm{C}$ or $\geq 38^{\circ} \mathrm{C}$ in 2 measurements separated by at least 1 hour

Definition of neutropenia: ANC $\leq 500 / \mathrm{mm}^{3}$

Expected neutropenia duration: not restricted

Interventions

- Antibiotic therapy before randomisation: IV ceftriaxone for low-risk patients and IV ceftazidime + IV amikacin +/- anti-gram-positive beta-lactam or glycopepide for high-risk patients

- Day start (day of randomisation): after 48 hours from hospitalisation (day 3)

- Management after randomisation:

- Short-therapy arm: all antibiotic stopped

- Long-therapy arm: continuation of the same regimen

- Planned duration of antibiotic treatment:

- * Short-therapy arm: 3 days, stopped at randomisation

* Long-therapy arm: 7 days if afebrile for 24 hours and CRP $<40 \mathrm{mg} / \mathrm{L}$

- Follow-up: until fever and neutropenia resolution

Outcomes

Primary outcome: number of episodes with uneventful resolution

Mortality outcome definition: not specified

Other relevant outcomes:

- Clinical failure: defined as need for change or re-instalment of antimicrobial therapy

- Number of fever days from randomisation

- Total antibiotic days from randomisation

- Any bacteraemia after randomisation

- Any documented infection after randomisation

- Development of antibiotic resistance: reported isolation of ESBL bacteria

- Length of hospitalisation

Full agreement between outcomes in registry versus results: no registry

Full agreement between outcomes in methods versus results: yes

Funding source: government-sponsored

Early discontinuation of antibiotics for febrile neutropenia versus continuation until neutropenia resolution in people with cancer (Review)

Copyright @ 2019 The Cochrane Collaboration. Published by John Wiley \& Sons, Ltd. 
Santolaya 2017 (Continued)

Risk of bias

\begin{tabular}{|c|c|c|}
\hline Bias & Authors' judgement & Support for judgement \\
\hline $\begin{array}{l}\text { Random sequence genera- } \\
\text { tion (selection bias) }\end{array}$ & Unclear risk & Using statistical software \\
\hline $\begin{array}{l}\text { Allocation concealment } \\
\text { (selection bias) }\end{array}$ & Unclear risk & Not specified \\
\hline $\begin{array}{l}\text { Blinding of participants } \\
\text { and personnel (perfor- } \\
\text { mance bias) } \\
\text { All outcomes }\end{array}$ & High risk & No blinding \\
\hline $\begin{array}{l}\text { Blinding of outcome as- } \\
\text { sessment (detection bias) } \\
\text { All outcomes }\end{array}$ & Low risk & Outcome assessor was blinded. \\
\hline $\begin{array}{l}\text { Incomplete outcome data } \\
\text { (attrition bias) } \\
\text { All outcomes }\end{array}$ & Low risk & No post randomisation dropouts \\
\hline $\begin{array}{l}\text { Selective reporting (re- } \\
\text { porting bias) }\end{array}$ & High risk & No registry \\
\hline Other bias & Low risk & Sample calculation with no early stop \\
\hline
\end{tabular}

\section{Abbreviations}

ANC: absolute neutrophil count

CRP: C-reactive protein

ESBL: extended-spectrum beta-lactamase

IQR: interquartile range

ITT: intention-to-treat

IV: intravenous

NA: non-available

SD: standard deviation

Characteristics of excluded studies [ordered by study ID]

\begin{tabular}{ll}
\hline Study & Reason for exclusion \\
\hline Aoun 1998 & Patients who were neutropenic were excluded. \\
\hline Aquino 1997 & Not randomised \\
\hline Calandra 1987 & Antibiotic therapy was continued in both study arms. \\
\hline Cherif 2004 & Participants were randomised to the type of antibiotic therapy, not to the duration of therapy. \\
\hline Cohen 1995 & Not randomised \\
\hline Horowitz 1996 & Antibiotic therapy was continued in both study arms. \\
\hline Idelevich 2015 & $\begin{array}{l}\text { Multiplex PCR was assessed as a diagnostic test with potential to shorten antibiotic duration, but } \\
\text { there was no predefined attempt to stop antibiotics before neutropenia resolution, and the study }\end{array}$ \\
\hline
\end{tabular}

Early discontinuation of antibiotics for febrile neutropenia versus continuation until neutropenia resolution in people with cancer 


\begin{tabular}{ll}
\hline Study & Reason for exclusion \\
\hline Lee 1998 & $\begin{array}{l}\text { did not report the number of participants who were still neutropenic at the time of treatment dis- } \\
\text { continuation in the intervention arm. }\end{array}$ \\
\hline Lima 2016 & $\begin{array}{l}\text { Pot randomised } \\
\text { predefined attempt to stop antibiotics before neutropenia resolution, and the study did not report } \\
\text { the number of participants who were still neutropenic at the time of treatment discontinuation in } \\
\text { the intervention arm. }\end{array}$ \\
\hline Pegram 1989 & Antibiotic therapy was continued in both study arms.
\end{tabular}

\section{Abbreviations}

PCR: polymerase chain reaction

\section{DATA AND ANALYSES}

\section{Comparison 1. Early discontinuation versus treatment until neutropenia resolution}

\begin{tabular}{|c|c|c|c|c|}
\hline Outcome or subgroup title & No. of studies & $\begin{array}{l}\text { No. of partici- } \\
\text { pants }\end{array}$ & Statistical method & Effect size \\
\hline 1 Mortality & 8 & 603 & Risk Ratio (M-H, Fixed, 95\% Cl) & $1.38[0.73,2.62]$ \\
\hline $\begin{array}{l}2 \text { Mortality - risk difference, by } \\
\text { day of randomisation }\end{array}$ & 8 & 603 & $\begin{array}{l}\text { Risk Difference (M-H, Fixed, 95\% } \\
\mathrm{Cl})\end{array}$ & $0.02[-0.02,0.05]$ \\
\hline $\begin{array}{l}3 \text { Mortality - risk difference, per } \\
\text { protocol AG2017 }\end{array}$ & 8 & 512 & $\begin{array}{l}\text { Risk Difference (M-H, Fixed, 95\% } \\
\mathrm{Cl})\end{array}$ & $0.03[-0.01,0.06]$ \\
\hline $\begin{array}{l}4 \text { Mortality - by inclusion of } \\
\text { febrile vs afebrile participants }\end{array}$ & 6 & 371 & $\begin{array}{l}\text { Risk Difference (M-H, Fixed, 95\% } \\
\mathrm{Cl})\end{array}$ & $0.04[-0.01,0.08]$ \\
\hline 4.1 Febrile participants & 4 & 253 & $\begin{array}{l}\text { Risk Difference (M-H, Fixed, 95\% } \\
\mathrm{Cl})\end{array}$ & $0.02[-0.04,0.08]$ \\
\hline 4.2 Afebrile participants & 3 & 118 & $\begin{array}{l}\text { Risk Difference (M-H, Fixed, 95\% } \\
\mathrm{Cl})\end{array}$ & $0.07[-0.01,0.15]$ \\
\hline $\begin{array}{l}5 \text { Mortality - by allocation con- } \\
\text { cealment }\end{array}$ & 8 & 603 & $\begin{array}{l}\text { Risk Difference (M-H, Fixed, 95\% } \\
\mathrm{Cl})\end{array}$ & $0.02[-0.02,0.05]$ \\
\hline $\begin{array}{l}5.1 \text { Low risk of bias for allocation } \\
\text { concealment }\end{array}$ & 2 & 230 & $\begin{array}{l}\text { Risk Difference (M-H, Fixed, 95\% } \\
\mathrm{Cl})\end{array}$ & $-0.02[-0.05,0.02]$ \\
\hline $\begin{array}{l}5.2 \text { Unclear risk of bias for alloca- } \\
\text { tion concealment }\end{array}$ & 6 & 373 & $\begin{array}{l}\text { Risk Difference (M-H, Fixed, 95\% } \\
\mathrm{Cl} \text { ) }\end{array}$ & $0.04[-0.01,0.09]$ \\
\hline 6 Total febrile days & 4 & 458 & $\begin{array}{l}\text { Mean Difference (IV, Fixed, 95\% } \\
\mathrm{Cl} \text { ) }\end{array}$ & $-0.64[-0.96,-0.32]$ \\
\hline 7 Clinical failure & 7 & 645 & Risk Ratio (M-H, Fixed, 95\% Cl) & $1.23[0.85,1.77]$ \\
\hline
\end{tabular}




\begin{tabular}{lllll}
\hline Outcome or subgroup title & No. of studies & $\begin{array}{l}\text { No. of partici- } \\
\text { pants }\end{array}$ & Statistical method & Effect size \\
\hline 8 Any bacteraemia & 8 & 662 & Risk Ratio (M-H, Fixed, 95\% Cl) & $1.56[0.91,2.66]$ \\
\hline 9 Any documented infection & 8 & 662 & Risk Ratio (M-H, Fixed, 95\% Cl) & $1.67[1.08,2.57]$ \\
\hline 10 Any fungal infection & 8 & 662 & $\begin{array}{l}\text { Risk Ratio (M-H, Random, 95\% } \\
\text { Cl) }\end{array}$ & $0.86[0.32,2.31]$ \\
\hline 11 Development of resistance & 4 & 340 & Risk Ratio (M-H, Fixed, 95\% Cl) & $1.49[0.62,3.61]$ \\
\hline
\end{tabular}

Analysis 1.1. Comparison 1 Early discontinuation versus treatment until neutropenia resolution, Outcome 1 Mortality.

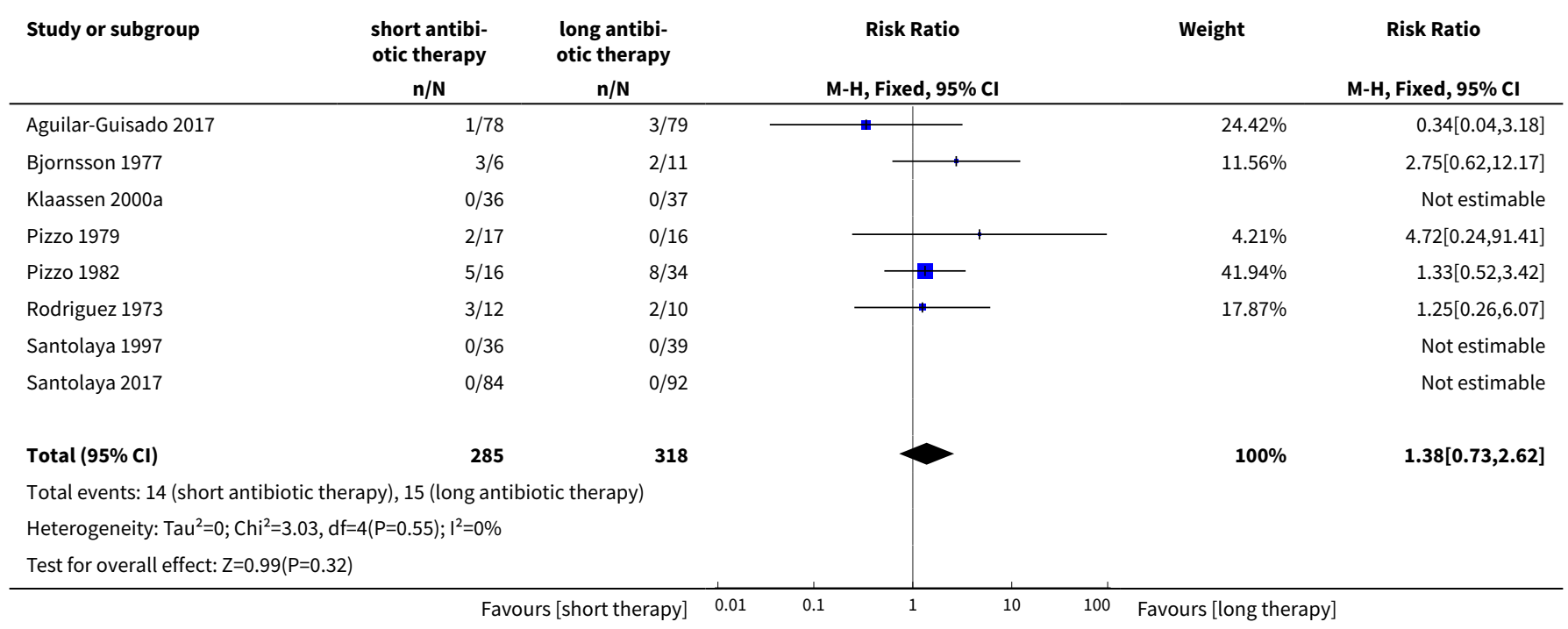

Analysis 1.2. Comparison 1 Early discontinuation versus treatment until neutropenia resolution, Outcome 2 Mortality - risk difference, by day of randomisation.

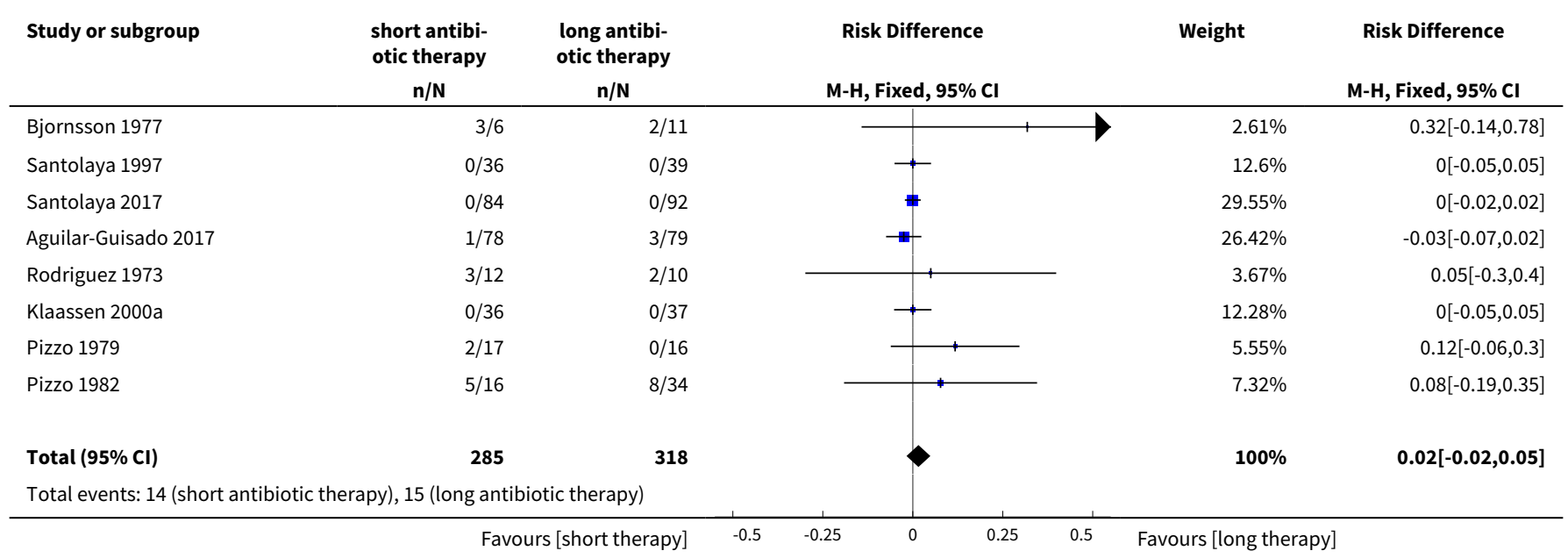




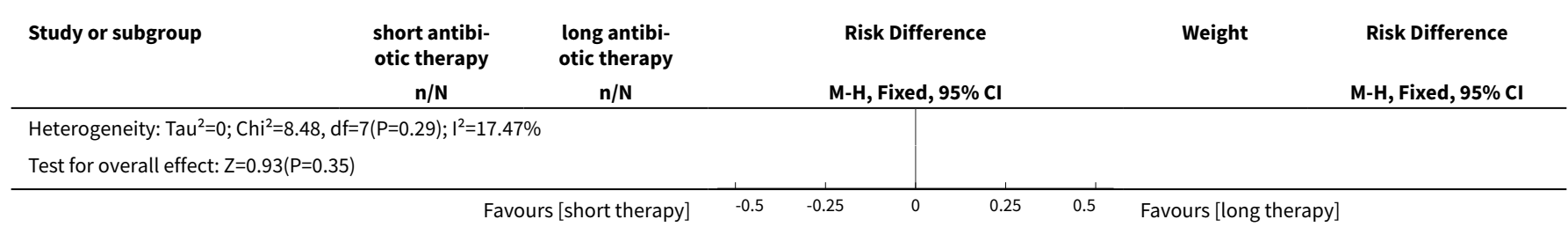

Analysis 1.3. Comparison 1 Early discontinuation versus treatment until neutropenia resolution, Outcome 3 Mortality - risk difference, per protocol AG2017.

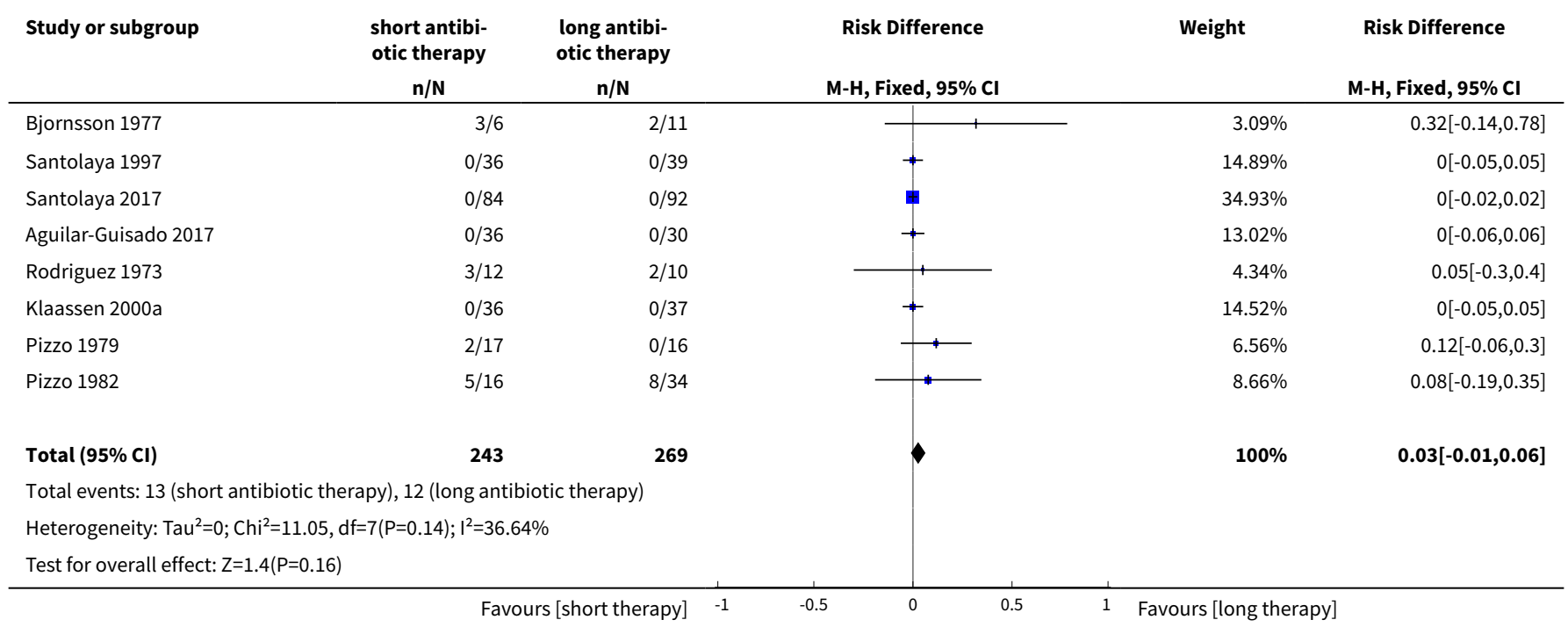

\section{Analysis 1.4. Comparison 1 Early discontinuation versus treatment until neutropenia} resolution, Outcome 4 Mortality - by inclusion of febrile vs afebrile participants.

\begin{tabular}{|c|c|c|c|c|c|}
\hline Study or subgroup & $\begin{array}{c}\text { short antibi- } \\
\text { otic therapy } \\
n / N\end{array}$ & $\begin{array}{c}\text { long antibi- } \\
\text { otic therapy } \\
n / N\end{array}$ & $\begin{array}{c}\text { Risk Difference } \\
\text { M-H, Fixed, 95\% Cl }\end{array}$ & Weight & $\begin{array}{c}\text { Risk Difference } \\
\text { M-H, Fixed, 95\% CI }\end{array}$ \\
\hline \multicolumn{6}{|c|}{ 1.4.1 Febrile participants } \\
\hline Bjornsson 1977 & $3 / 6$ & $2 / 11$ & & $4.3 \%$ & $0.32[-0.14,0.78]$ \\
\hline Pizzo 1982 & $5 / 16$ & $8 / 34$ & & $12.06 \%$ & $0.08[-0.19,0.35]$ \\
\hline Rodriguez 1973 & $0 / 4$ & $2 / 6$ & & $2.66 \%$ & $-0.33[-0.78,0.11]$ \\
\hline Subtotal $(95 \% \mathrm{Cl})$ & 110 & 143 & & $67.69 \%$ & $0.02[-0.04,0.08]$ \\
\hline \multicolumn{6}{|c|}{ Total events: 8 (short antibiotic therapy), 12 (long antibiotic therapy) } \\
\hline \multicolumn{6}{|c|}{ Heterogeneity: $\operatorname{Tau}^{2}=0 ; \mathrm{Chi}^{2}=7.69, \mathrm{df}=3(\mathrm{P}=0.05) ; \mathrm{I}^{2}=61.01 \%$} \\
\hline \multicolumn{6}{|c|}{ Test for overall effect: $\mathrm{Z}=0.66(\mathrm{P}=0.51)$} \\
\hline \multicolumn{6}{|c|}{ 1.4.2 Afebrile participants } \\
\hline Pizzo 1979 & $2 / 17$ & $0 / 16$ & 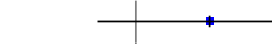 & $9.14 \%$ & $0.12[-0.06,0.3]$ \\
\hline Rodriguez 1973 & $3 / 8$ & $0 / 4$ & & $2.96 \%$ & $0.38[-0.04,0.79]$ \\
\hline Subtotal $(95 \% \mathrm{CI})$ & 61 & 57 & & $32.31 \%$ & $0.07[-0.01,0.15]$ \\
\hline
\end{tabular}

Early discontinuation of antibiotics for febrile neutropenia versus continuation until neutropenia resolution in people with cancer 38 (Review)

Copyright (c) 2019 The Cochrane Collaboration. Published by John Wiley \& Sons, Ltd. 


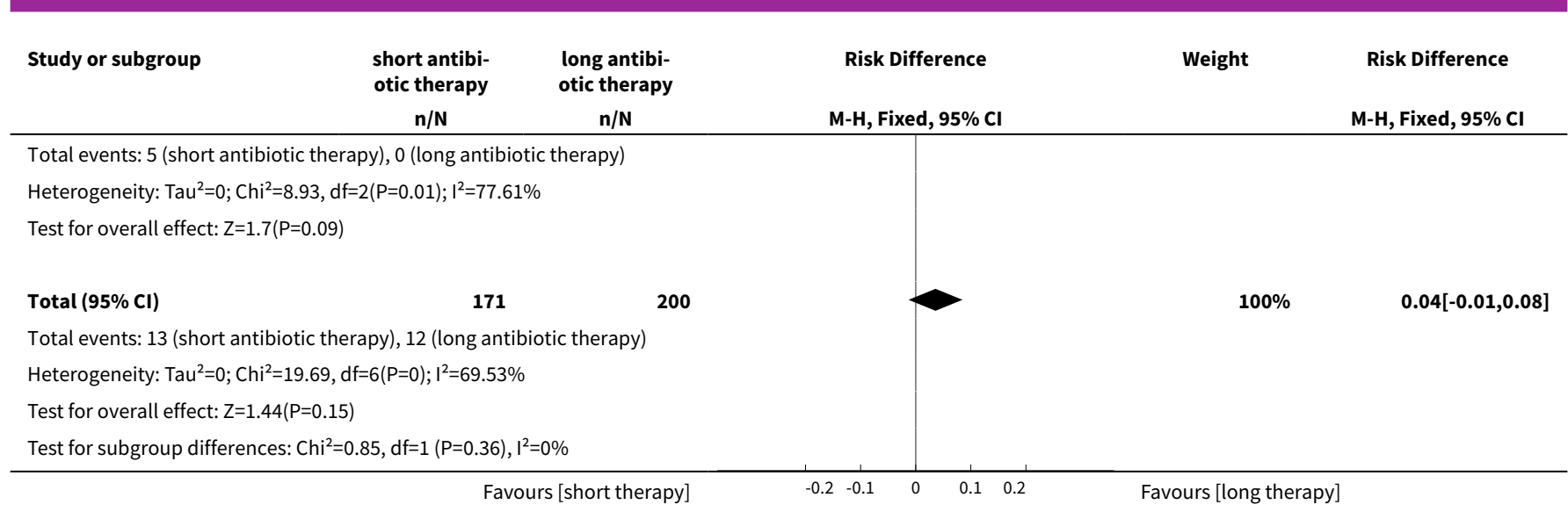

\section{Analysis 1.5. Comparison 1 Early discontinuation versus treatment until neutropenia resolution, Outcome 5 Mortality - by allocation concealment.}

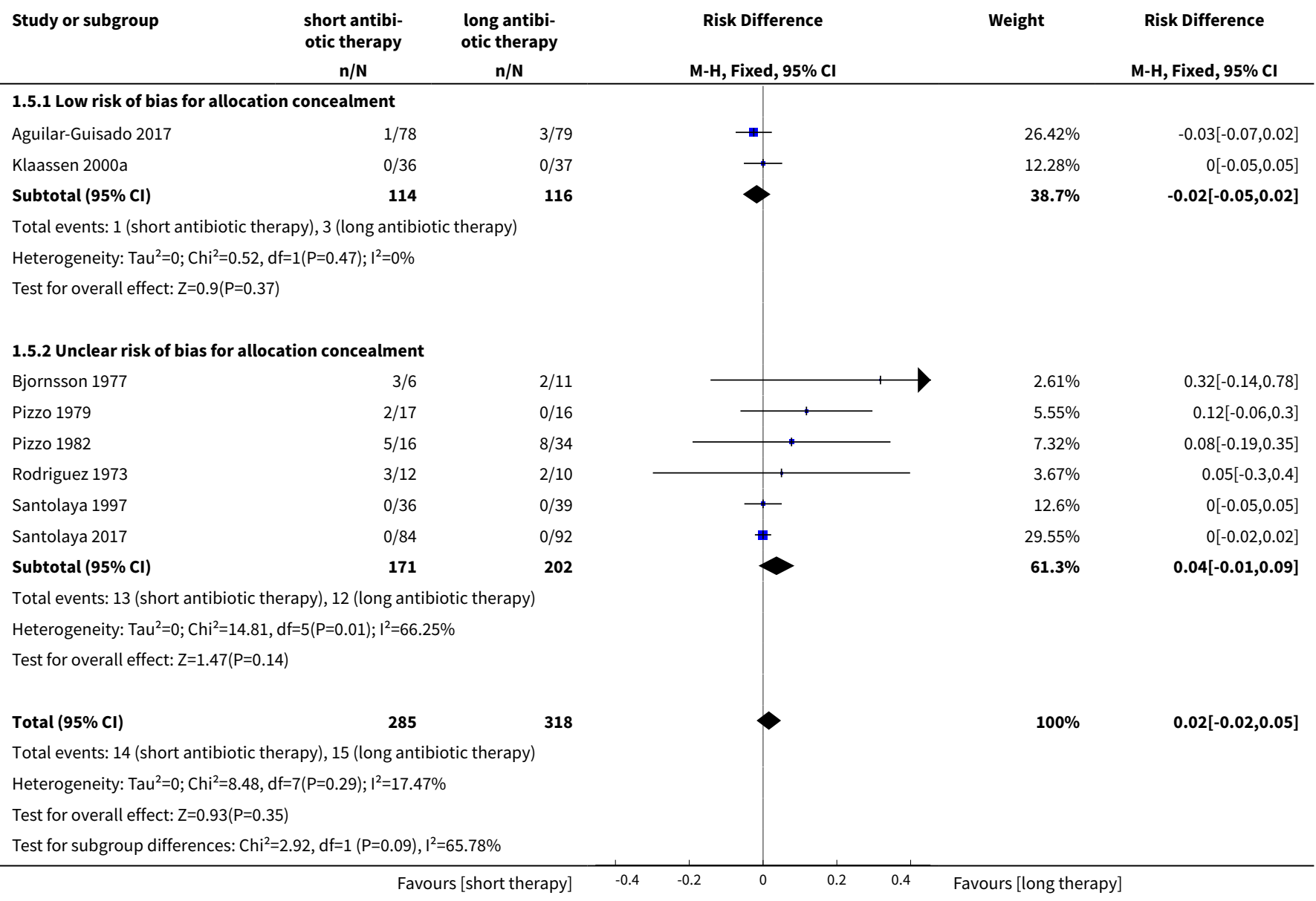

Early discontinuation of antibiotics for febrile neutropenia versus continuation until neutropenia resolution in people with cancer 
Analysis 1.6. Comparison 1 Early discontinuation versus treatment until neutropenia resolution, Outcome 6 Total febrile days.

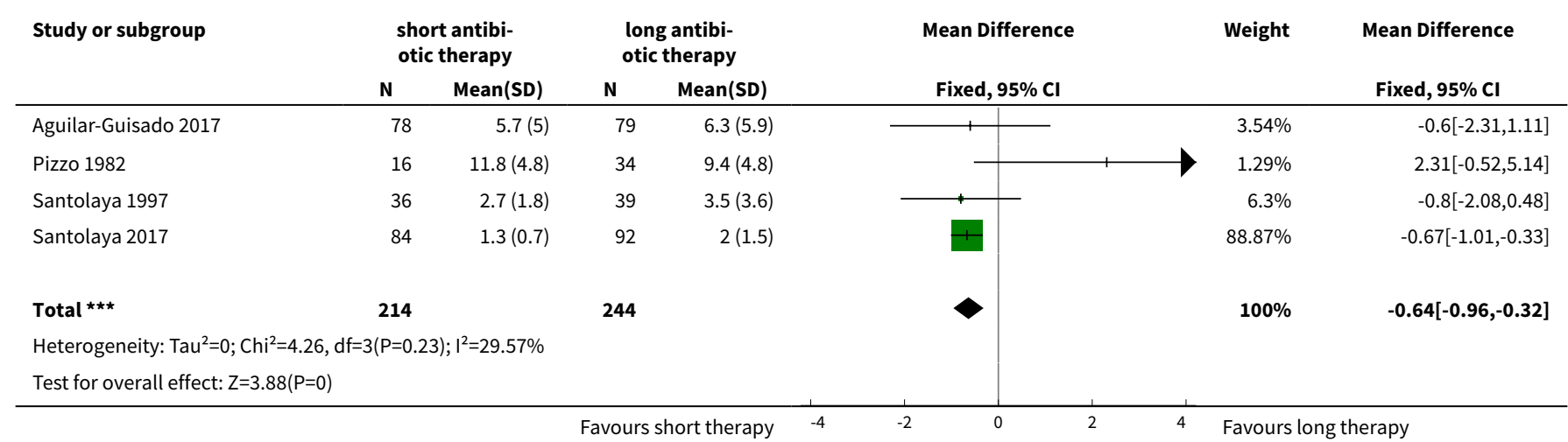

Analysis 1.7. Comparison 1 Early discontinuation versus treatment until neutropenia resolution, Outcome 7 Clinical failure.

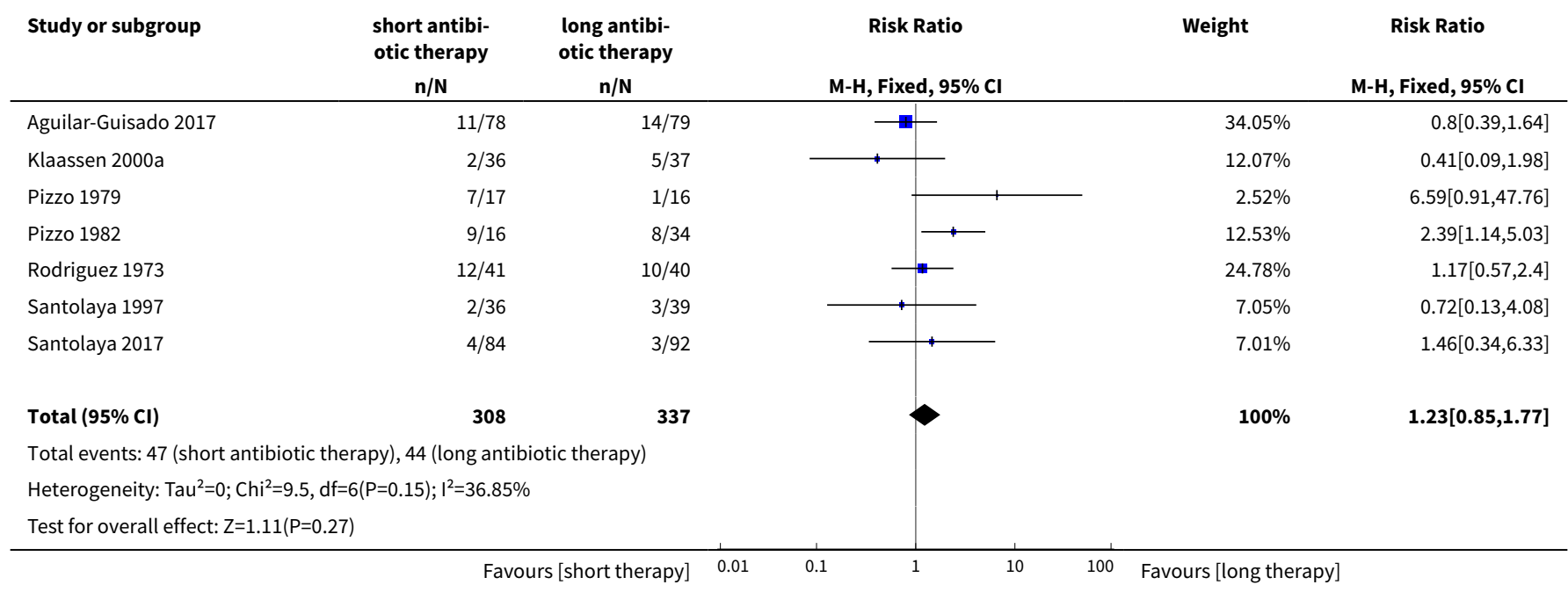

Analysis 1.8. Comparison 1 Early discontinuation versus treatment until neutropenia resolution, Outcome 8 Any bacteraemia.

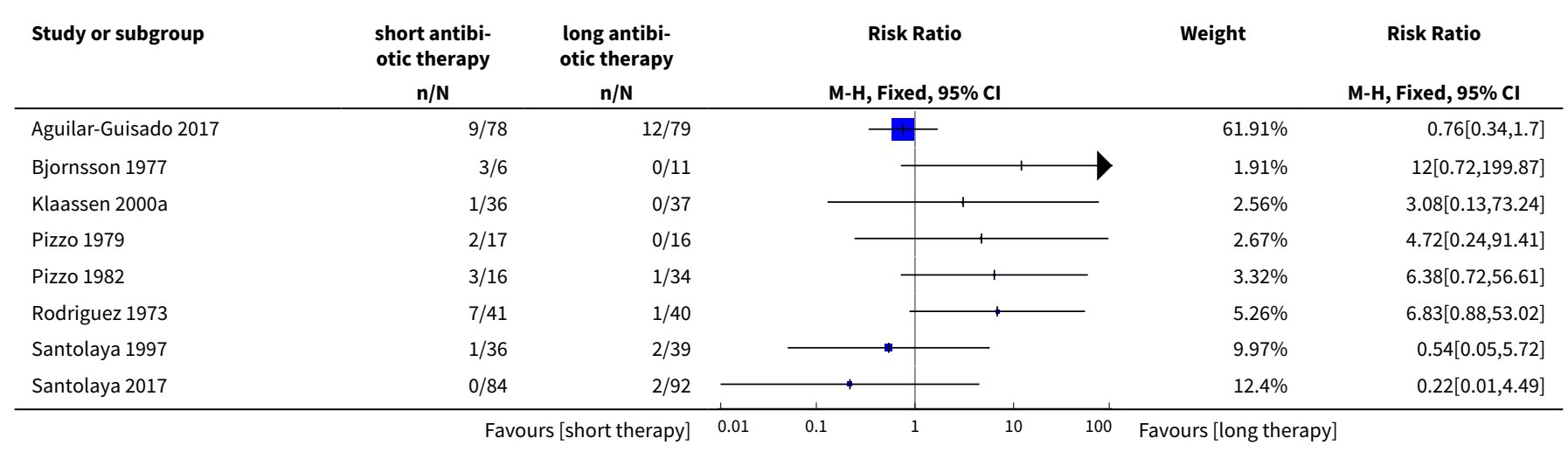

Early discontinuation of antibiotics for febrile neutropenia versus continuation until neutropenia resolution in people with cancer 40 


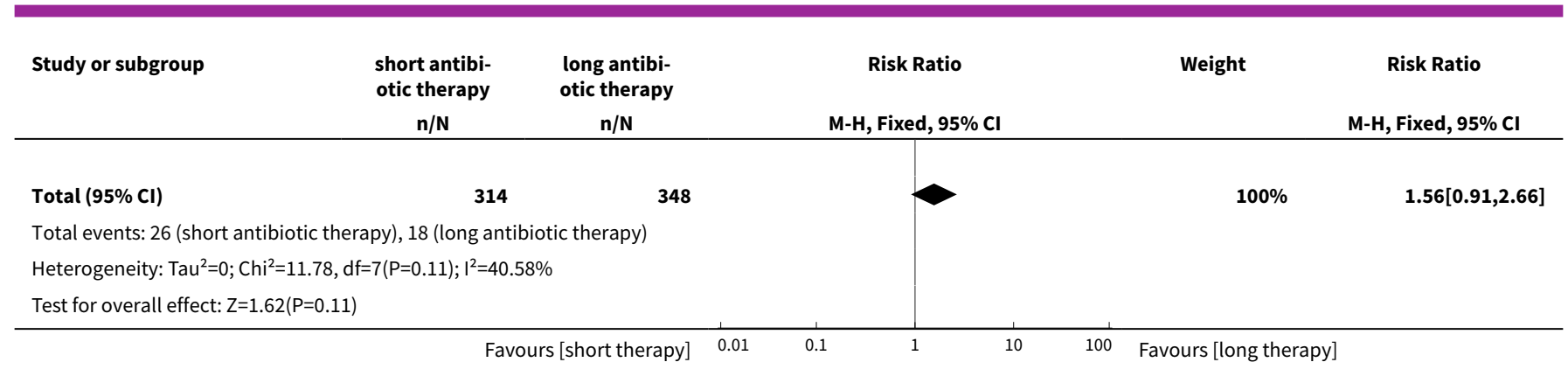

Analysis 1.9. Comparison 1 Early discontinuation versus treatment until neutropenia resolution, Outcome 9 Any documented infection.

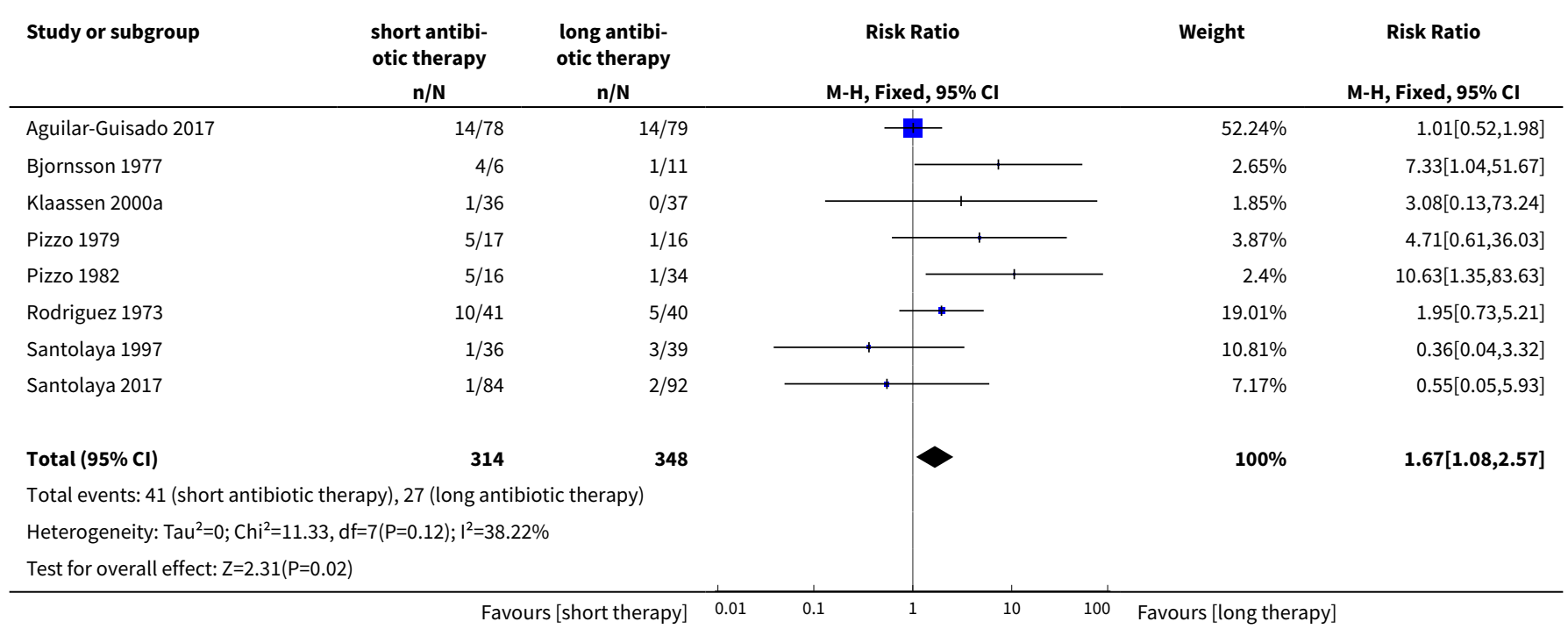

\section{Analysis 1.10. Comparison 1 Early discontinuation versus treatment until neutropenia resolution, Outcome 10 Any fungal infection.}

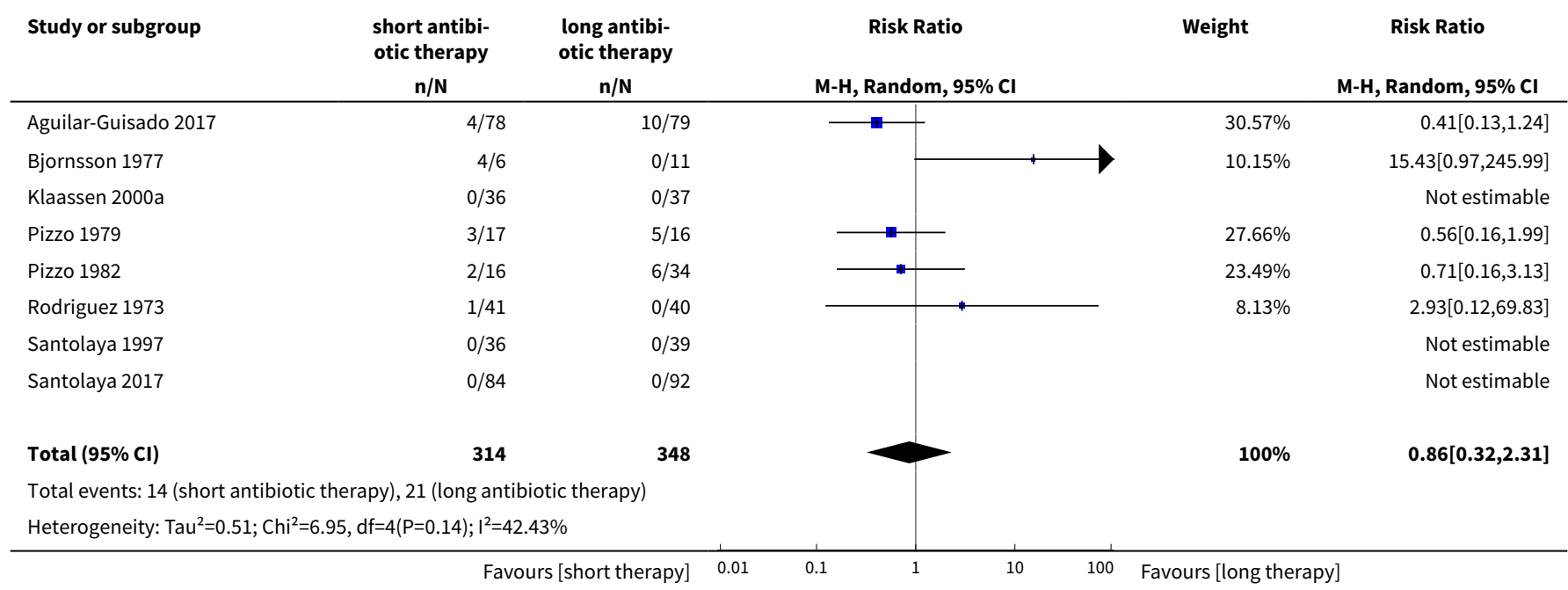




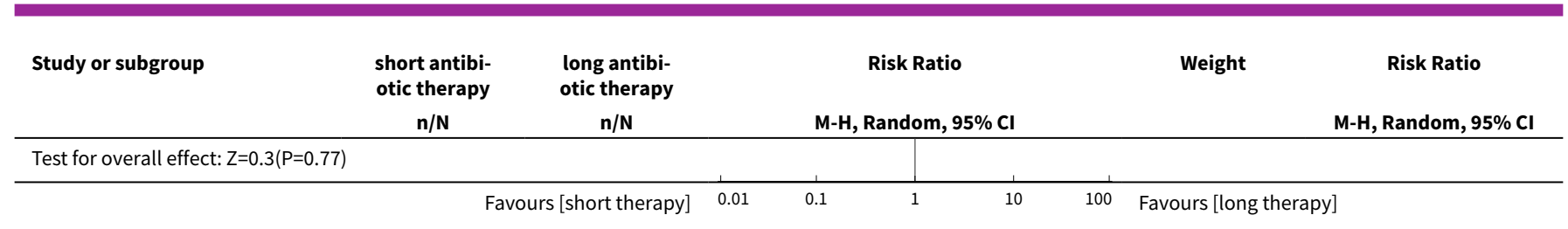

\section{Analysis 1.11. Comparison 1 Early discontinuation versus treatment until neutropenia resolution, Outcome 11 Development of resistance.}

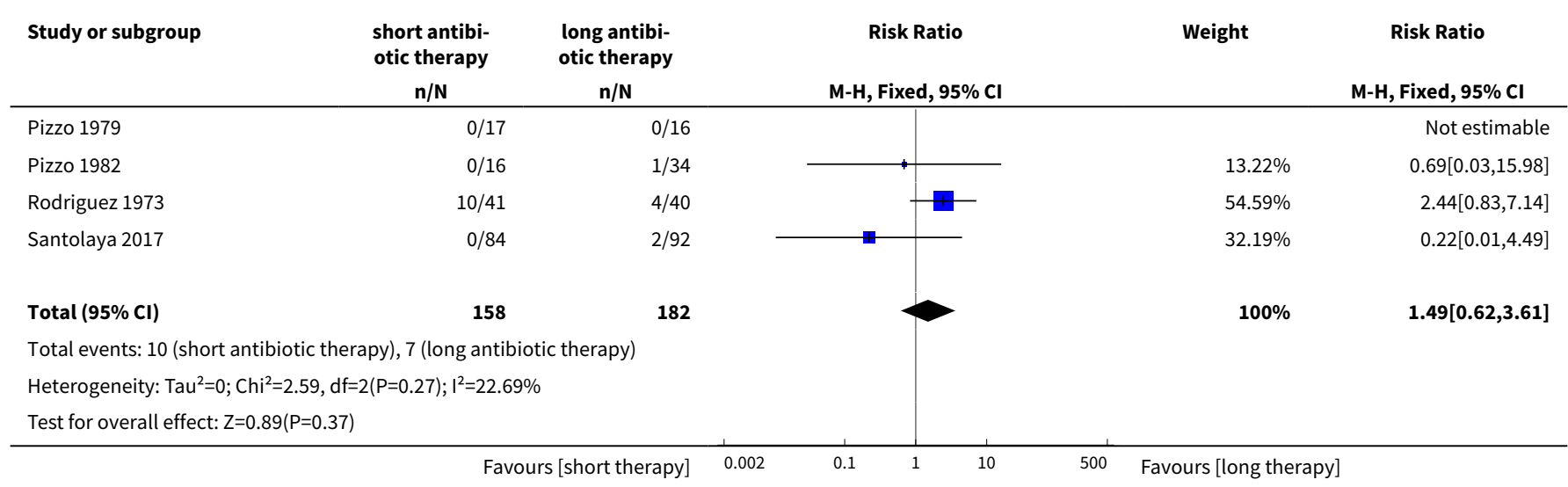

\section{ADDITIONAL TABLES}

Table 1. Guideline recommendations regarding antibiotic usage duration in febrile neutropenia

\begin{tabular}{ll}
\hline Guidelines & Recommendation for documented infec- \\
& tion
\end{tabular}

The Infectious Diseases Society of America (IDSA) clinical practice guidelines for the use of antimicrobial agents in neutropenic patients with cancer (Freifeld 2011)
Duration of antibiotic therapy dictated by the particular organism and site; appropriate antibiotics should continue for at least the duration of neutropenia (until absolute neutrophil count is $>500$ cells $/ \mathrm{mm}^{3}$ ), or longer if clinically necessary.
Initial regimen continued until clear signs of marrow recovery. An option is given, if an appropriate treatment course has been completed and all signs and symptoms of a documented infection have resolved, to resume oral fluoroquinolone prophylaxis until marrow recovery.
European guidelines for empirical antibacterial therapy for febrile neutropenic patients in the era of growing resistance: summary of the 2011 4th European Conference on Infections in Leukemia (ECIL-4) (Averbuch 2013a; Averbuch 2013b)
Targeted antibiotics should be continued until infection is microbiologically eradicated and all clinical signs of infection are resolved for at least 7 days, of which at least 4 days are afebrile.
Intravenous empirical antibacterial therapy may be discontinued after $\geq 72 \mathrm{~h}$ in patients who have been afebrile $\geq 48 \mathrm{~h}$ and are stable, irrespective of neutrophil count or expected duration of neutropenia.
The United Kingdom National Institute for Health and Care Excellence (NICE) guidelines for prevention and management of neutropenic sepsis in cancer patients (Phillips 2012)
Discontinue empiric antibiotic therapy in patients whose neutropenic sepsis has responded to treatment, irrespective of neutrophil count.
Discontinue empiric antibiotic therapy in patients whose neutropenic sepsis has responded to treatment, irrespective of neutrophil count. 


\section{Table 1. Guideline recommendations regarding antibiotic usage duration in febrile neutropenia (Continued)}

The European Society for Medical Oncology (ESMO) guidelines for the management of febrile neutropenia, 2010 (de Naurois 2010)
Antibacterial therapy may be stopped in patients who suffered no complications and have been afebrile for at least 5 to 7 days, except in certain high-risk cases such as patients with acute leukaemia or following high-dose chemotherapy, in which longer courses of antibiotics or continuation until marrow recovery is recommended.

In low-risk patients who remain neutropenic, antibiotic therapy may be withheld after a minimum of 15 days without fever. High-risk patients should receive antibiotic therapy until there is neutrophil recovery.
Antibacterial therapy may be stopped in patients who suffered no complications and have been afebrile for at least 5 to 7 days, except in certain high-risk cases such as patients with acute leukaemia or following high-dose chemotherapy, in which longer courses of antibiotics or continuation until marrow recovery is recommended.

In low-risk patients who remain neutropenic, antibiotic therapy may be withheld after a minimum of 15 days without fever. High-risk patients should receive antibiotic therapy until there is neutrophil recovery.

\footnotetext{
Infectious Diseases Working Party of the German Society of Hematology and Medical Oncology (AGIHO) for the management of sepsis in neutropenic patients, updated in 2014 (Penack 2014)
} Not addressed Not addressed

\begin{tabular}{l}
\hline Australian consensus guidelines for the Not addressed $\quad$ Not addressed \\
management of neutropenic fever in \\
adult cancer patients 2010/2011 (Lin- \\
garatnam 2011)
\end{tabular}




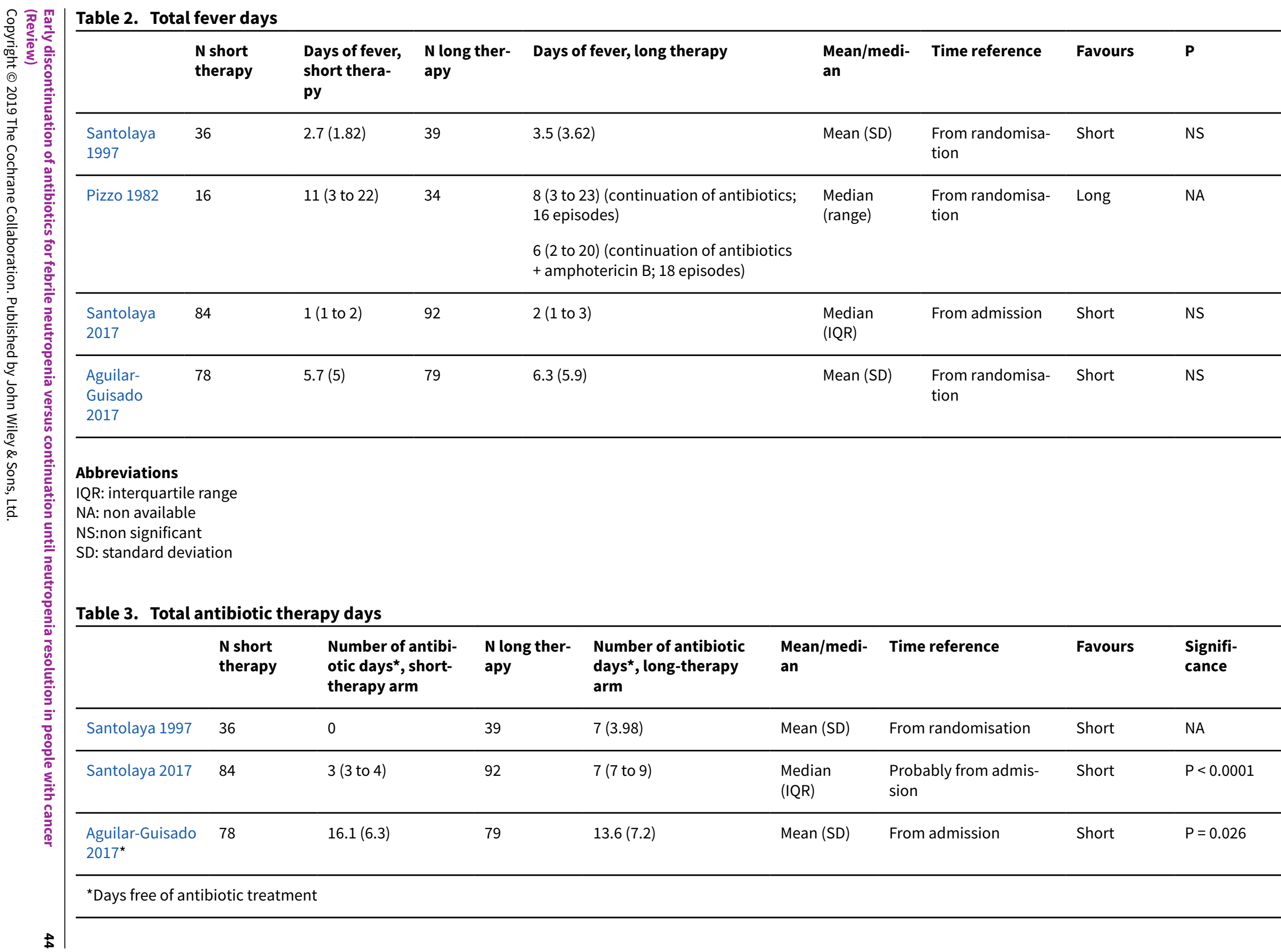




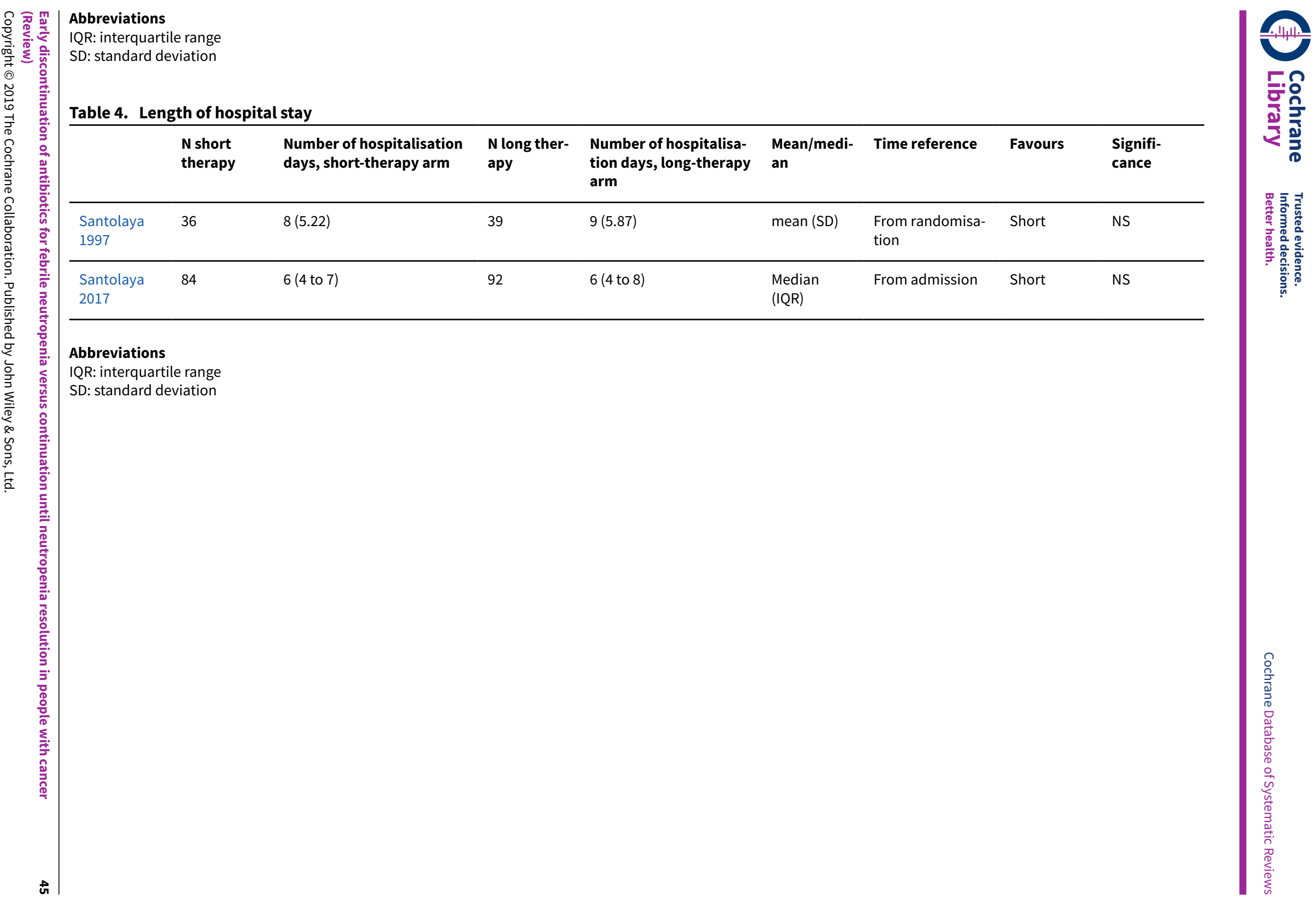




\section{AP PE N DICES}

\section{Appendix 1. MEDLINE search strategy}

1. Neutropenia/

2. (neutropaeni ${ }^{\star}$ or neutropeni ${ }^{\star}$ or granulocytopeni ${ }^{\star}$ or granulocytopaeni $\left.{ }^{\star}\right) . m p$.

3. 1 or 2

4. exp Anti-Infective Agents/

5. (antibiotic ${ }^{\star}$ or antimicrobial ${ }^{\star}$ or anti-microbial ${ }^{\star}$ or antibacterial ${ }^{\star}$ or anti-bacterial ${ }^{\star}$ ).mp.

6.4 or 5

7. (duration or continue* or continuation or carry on or discontinue* or discontinuation or stop $\left.{ }^{\star}\right) . m p$.

8.3 and 6 and 7

9. randomized controlled trial.pt.

10. controlled clinical trial.pt.

11. randomized.ab.

12. placebo.ab.

13. clinical trials as topic.sh.

14. randomly.ab.

15. trial.ti.

16.9 or 10 or 11 or 12 or 13 or 14 or 15

17. 8 and 16

18. (animals not (humans and animals)).sh.

19. 17 not 18

Key $\mathrm{mp}=$ title, abstract, original title, name of substance word, subject heading word, keyword heading word, protocol supplementary concept word, rare disease supplementary concept word, unique identifier

\section{Appendix 2. Embase search strategy}

1. exp neutropenia/

2. (neutropaeni ${ }^{\star}$ or neutropeni* ${ }^{\star}$ or granulocytopeni* or granulocytopaeni $\left.{ }^{\star}\right) . \mathrm{mp}$.

3. 1 or 2

4. exp Anti-Infective Agents/

5. (antibiotic ${ }^{\star}$ or antimicrobial ${ }^{\star}$ or anti-microbial ${ }^{\star}$ or antibacterial ${ }^{\star}$ or anti-bacterial $\left.{ }^{\star}\right) \cdot \mathrm{mp}$.

6.4 or 5

7. (duration or continue ${ }^{\star}$ or continuation or carry on or discontinue ${ }^{\star}$ or discontinuation or stop ${ }^{\star}$ ).mp.

8. 3 and 6 and 7

9. crossover procedure/

10. double-blind procedure/

11. randomized controlled trial/

12. single-blind procedure/

13. random ${ }^{\star} . \mathrm{mp}$.

14. factorial ${ }^{\star} \cdot \mathrm{mp}$.

15. (crossover ${ }^{\star}$ or cross over ${ }^{\star}$ or cross-over $\left.^{\star}\right) . \mathrm{mp}$.

16. placebo*.mp.

17. (double* adj blind $\left.{ }^{\star}\right) \cdot \mathrm{mp}$.

18. (singl ${ }^{\star}$ adj blind $\left.{ }^{\star}\right) \cdot m p$.

19. assign ${ }^{\star} . \mathrm{mp}$.

20. allocat ${ }^{\star} \cdot \mathrm{mp}$.

21. volunteer ${ }^{\star} . \mathrm{mp}$.

22.9 or 10 or 11 or 12 or 13 or 14 or 15 or 16 or 17 or 18 or 19 or 20 or 21

23. 8 and 22

Key $\mathrm{mp}=$ title, abstract, original title, name of substance word, subject heading word, keyword heading word, protocol supplementary concept word, rare disease supplementary concept word, unique identifier

\section{Appendix 3. CENTRAL search strategy}

1. MeSH descriptor: [Neutropenia] explode all trees

2. neutropaeni ${ }^{\star}$ or neutropeni ${ }^{\star}$ or granulocytopeni* or granulocytopaeni $^{\star}$

3. \#1 or \#2

4. MeSH descriptor: [Anti-Infective Agents] explode all trees

5. antibiotic $^{\star}$ or antimicrobial ${ }^{\star}$ or anti-microbial ${ }^{\star}$ or antibacterial ${ }^{\star}$ or anti-bacterial ${ }^{\star}$

Early discontinuation of antibiotics for febrile neutropenia versus continuation until neutropenia resolution in people with cancer (Review)

Copyright (C) 2019 The Cochrane Collaboration. Published by John Wiley \& Sons, Ltd. 
6. \#4 or \#5

7. Any MeSH descriptor with qualifier(s): [Administration \& dosage - AD]

8. duration or continue* or continuation or carry on or discontinue* or discontinuation or stop ${ }^{\star}$

9. \#8 or \#9

10. \#3 and \#7 and \#9

\section{CONTRIBUTIONS OF AUTHORS}

- Concept and design: all authors

- Search: Anat Stern, Elena Carrara, Roni Bitterman

- Data extraction: Anat Stern, Elena Carrara, Roni Bitterman

- Data entry into Review Manager 5 and review: Anat Stern, Mical Paul

- Data analysis: Anat Stern, Mical Paul

- Wrote the first version of the review: Anat Stern, Mical Paul

- Reviewed and comments on the review: all authors

\section{DECLARATIONS OF INTEREST}

Anat Stern: none known

Elena Carrara: none known

Roni Bitterman: none known

Dafna Yahav: none know

Leonard Leibovici: none known

Mical Paul: none known

\section{SOURCES OF SUPPORT}

\section{Internal sources}

- Internal, Other.

\section{External sources}

- No sources of funding, Other.

\section{DIFFERENCES BETWEEN PROTOCOLANDREVIEW}

We added risk difference analyses when a significant proportion of trials had zero events in both arms.

We performed a post hoc subgroup analysis for the primary outcome according to the inclusion of febrile versus afebrile participants.

\section{INDEX TERMS}

\section{Medical Subject Headings (MeSH)}

*Withholding Treatment; Anti-Bacterial Agents [ ${ }^{\star}$ therapeutic use]; Drug Resistance, Bacterial; Febrile Neutropenia [ ${ }^{*}$ drug therapy] [mortality]; Neoplasms [ ${ }^{*}$ complications]; Randomized Controlled Trials as Topic; Treatment Outcome

\section{MeSH check words}

Adult; Child; Humans 